\title{
Revision of Scotocyma Turner (Lepidoptera: Geometridae: Larentiinae)
}

\author{
Olga Schmidt \\ Zoologische Staatssammlung München, Münchhausenstraße 21, D-81247, München, Germany.
}

\begin{abstract}
The Australasian genus Scotocyma Turner is revised, containing the species S. albinotata (Walker), S. legalis (Warren), S. asiatica Holloway, S. scotopepla Prout, stat. n., S. manusensis Prout, stat. n., S. mimula (Warren), stat. n. and S. miscix Prout. Scotocyma euryochra Turner, syn. n., S. idioschema Turner, syn. n., S. ischnophrica Turner, syn. n. and S. transfixa Turner, syn. n. are regarded as synonyms of S. albinotata. Four species are described as new: S. samoensis, sp. n., S. sumatrensis, sp. n., S. rutilimixta, sp. n. and S. longiuncus, sp. n. Lectotypes are designated for S. scotopepla, S. manusensis and S. miscix. All species are illustrated, and keys to species and distribution maps are provided. A phylogenetic analysis was performed to test the monophyly of the genus and to examine distribution patterns of the species. A biogeographical discussion is included. The tribal position of the genus is clarified and relationships to closely related genera are discussed.
\end{abstract}

Key words Australasian region, biogeography, distribution patterns, geometrid moths, Melanesian island arcs, phylogenetics, taxonomy, Xanthorhoini.

\section{INTRODUCTION}

The genus Scotocyma Turner (1904) belongs to the large subfamily Larentiinae (Lepidoptera: Geometridae). The larentiine moths have a worldwide distribution, with the highest species diversity in temperate regions. The genus Scotocyma is atypical for the subfamily in this respect because it occurs mainly in tropical and subtropical regions. All known specimens were collected at light at night, suggesting that the species of Scotocyma are nocturnal. The genus currently contains eight described species with three subspecies, after synonymy of Scotocyma pteridophila (Turner) with Chaetolopha emporias (Turner) (Schmidt 2002). The wing pattern shows a high level of intraspecific variation that complicates the definition of species limits.

There have been no attempts to clarify the tribal position of Scotocyma. In the Checklist of the Lepidoptera of Australia the genus is placed at the end of the subfamily (McQuillan \& Edwards 1996). Likewise, Holloway (1998) left the genus unplaced, although he suggested that the calcar-like structure between the valve bases in the male genitalia (if homologous to calcar) may indicate affinity with the Xanthorhoini. However, a preliminary study of the male and female genitalia of Scotocyma and of Palaearctic and Australian xanthorhoine genera indicates that Scotocyma belongs in the tribe Xanthorhoini (Schmidt 2003). Australasia has a very rich and diverse fauna of Xanthorhoini, including presumably both primitive and more derived elements, with several genera showing considerable endemism, thus making the genus Scotocyma important from phylogenetic and biogeographical perspectives.

Email: olga.schmidt@zsm.mwn.de
Since Turner (1922), there have been few reviews of the Australasian genera of Larentiinae. Craw (1986, 1987) revised the New Zealand species of the genera Notoreas Meyrick and Helastia (Guenée). The Australian Anachloris Meyrick and Australasian Chaetolopha Warren have been revised recently by Schmidt (2001, 2002). Here, I continue this series of revisions on the Australasian larentiine fauna.

The primary aims of this article are to revise and illustrate the genus Scotocyma, to provide figures of male and female genitalia and to describe new species. A phylogenetic analysis is performed to investigate relationships within the genus and to provide basis for a biogeographical discussion. The tribal position of the genus and its relationship to closely related larentiine genera are discussed.

\section{MATERIALS AND METHODS}

About 150 specimens were studied from the following institutions: Australian Museum, Sydney (AMSA); Australian National Insect Collection, CSIRO, Canberra (ANIC); The Natural History Museum, London (BMNH); Bernice Pauahi Bishop Museum, Honolulu, Hawaii (BPBM); Museum Victoria, Melbourne (DEMV); Macleay Museum University of Sydney (MMUS); M. Sommerer Private Collection (MSPC); Smithsonian Institution, Washington, DC (NMNH); O. Schmidt Private Collection (OSPC); Zoologische Staatssammlung, Munich (ZSM). Initials used for collectors of the material are: AJT, AJ Turner; ASM, AS Meek; EDE, ED Edwards; IFBC, IFB Common; JDH, JD Holloway; LHMR, LH MosseRobinson; VJR, VJ Robinson. Other abbreviations are: coll., collection; distr., district; Mt, Mountain; N.P., National Park; nr, near. 
Wing expanse was measured as twice the distance from midthorax to the forewing apex. The dissected genitalia have been stained with chlorazol black and mounted on slides in euparal. Nomenclature for adult morphology and terminology for genitalia follow Pierce (1914), Forbes (1948), Klots (1970) and Nichols (1989).

The phylogenetic analysis was conducted using PAUP* version 4 b10 (Swofford 2002). Bremer support values were calculated with AutoDecay version 4.0 (Eriksson 1998) and PAUP*. Figure 77 was prepared using MacClade version 3.07 (Maddison \& Maddison 1992).

Photomicrographs were taken with a digital camera (ProgRes 3012, Jenoptic Laser Systems GmbH) attached to a microscope and processed with the AutoMontage system (versions 2.04 and 3.03, Synoptics Ltd). Photographs of adults were taken with a Nikon coolpix 950 and 990. The digital images were enhanced and the plates compiled with Adobe Photoshop and Adobe Illustrator.

\section{SYSTEMATICS}

\section{Scotocyma Turner}

Scotocyma Turner (1904): 245. Type species: Scotosia albinotata Walker (1866).

Paragramma Warren (1905): 424. Type species: Paragramma mimula Warren (1905).

Description (autapomorphies for the genus are given in bold). Head. Face with short cone of scales. Labial palpus thick, short, curved, exceeding frons by less than one-third diameter of eye, with terminal segment small, blunt. Antenna in males thicker than in females, simple in both sexes. Thorax. Smoothly scaled, pale yellowish or whitish ventrally. First and sometimes second pair of legs dark, often with rings of paler scales. Foretibia with a long, dense basal hair tuft, closely appressed to tibia in both sexes. Hind tibia with two pairs of spurs. Wings (Figs 1-15,16-21,22-36). Wing expanse 27$42 \mathrm{~mm}$. Forewing with median band forming tooth-like medial projection outwards; costa slightly to moderately curved distally, apex slightly rounded, termen bowed, finely crenulate; one rather small areole present in both sexes. Hind wing with termen rounded, crenulate, with anal angle well expressed. Wing colouration variable, above with brown colours dominating, often with moderate to extensive white blotching, underneath with contrasting whitish or yellowish bands, with a discal dot. Abdomen. Coremata present in males, consisting of eversible, reddish-brown to blackishbrown hair tufts in a broad pocket laterally on each side of the seventh segment (Fig. 37). Additionally, a thin, weakly sclerotised ring between the seventh and the eighth segments is present, with a small medial sclerite attached (Figs 38-40). The last pair of abdominal spiracles set ventrally on the coremata pockets.

Male genitalia (Figs 41-52,53-58). Uncus sclerotised, simple or broadened distally, with its base modified, with lateral areas membranous; socii absent. Tegumen cupola-shaped, relatively short, usually with sclerotised, sometimes serrated, arms. Valva narrowed medially, broadly connected to the vinculum, with costa broad, often sclerotised, with comblike structures set on broadenings at the valval sacculi. Vinculum U- or V-shaped, narrow or broadened, without distinct saccus; calcar present, usually placed close to vinculum, with broad hood-shaped membrane connected to its basis. Aedeagus thick, short, with proximal coecum penis usually very short, oblique-rounded, cornuti sometimes present.

Female genitalia (Figs 59-62,63-70). Papillae anales short, broad at base, apices rounded. Apophyses posteriores thin and long, apophyses anteriores shorter, broadened distally. Antrum large, sclerotised, somewhat funnel-shaped, broadened distally, folded and flattened dorso-ventrally. Ductus bursae shortened, relatively broad, membranous. Corpus bursae membranous, with patches of scobinate or corrugate sclerotisation on its dorsal side, with large diverticulum narrowly attached at its distal region. Ductus seminalis thin, inserted ventrally on corpus bursae. Signum well developed, usually a patch of inwardly directed spicules on ventral side, patch size and shape variable.

Habitat. Subtropical and tropical primary forest at moderate elevations of 340-1800 m.

Distribution. Australasian region from Borneo, Sulawesi and Sumatra in the west through Papua New Guinea to Samoa, New Caledonia and Fiji in the east, and eastern Australia.

\section{Key to species of Scotocyma (males and females)}

I Foretibia frontally with basal deep-purple spot, with medial ring of purple and purple-brown scales. Fringe at hind margin of hind wing light, yellowish (Figs 16,18,19,21,33-35) ................ S. miscix Prout

- Foretibia frontally without basal deep-purple spot, sometimes with scales of different colour, without medial ring of purple and purple-brown scales, sometimes with rings of different colour. Fringe at hind margin of hind wing darker, usually greyish or brownish. .. 2

2 Wings underneath with vague marmoreal colouration in basal half. Hind wing underneath without discal dot (Figs 8,31) .............................. S. asiatica Holloway

- Wings underneath without marmoreal colouration. Hind wing underneath with a small or large discal dot (Figs 22-30,32,36) 3

3 Face covered mostly with black scales. Main colour of palpus is blackish-brown, not speckled with whitish scales. Foretibia and tarsus frontally blackish, without rings of lighter scales (Figs 5,7,36)

S. samoensis sp. n.

Face covered mostly with scales of other colour. Main colour of palpus is different, speckled with whitish scales. Foretibia and tarsus frontally brown to dark brown, with rings of lighter scales 


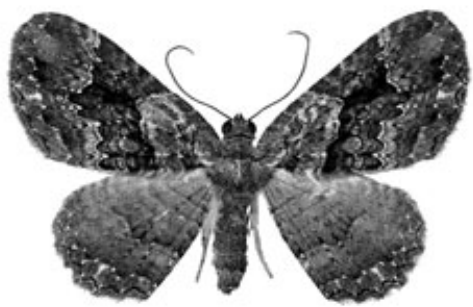

1
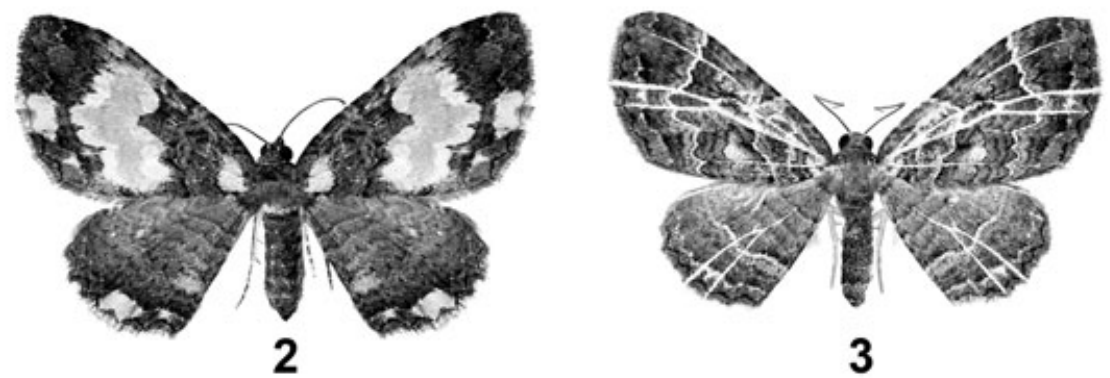

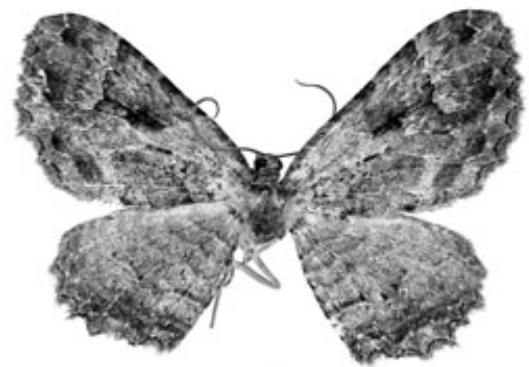

4
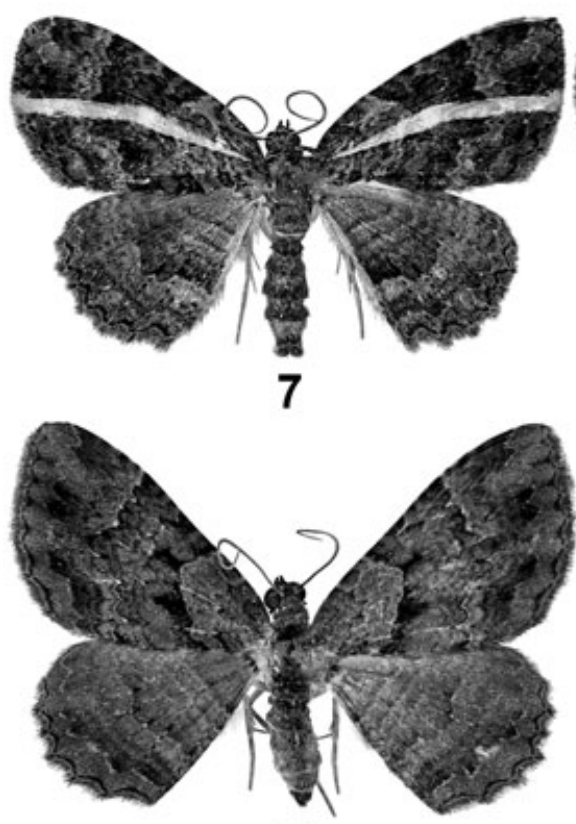

10

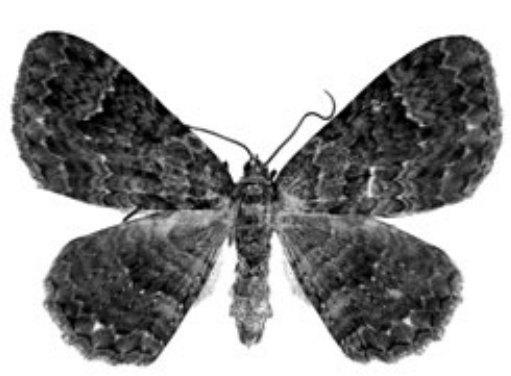

13

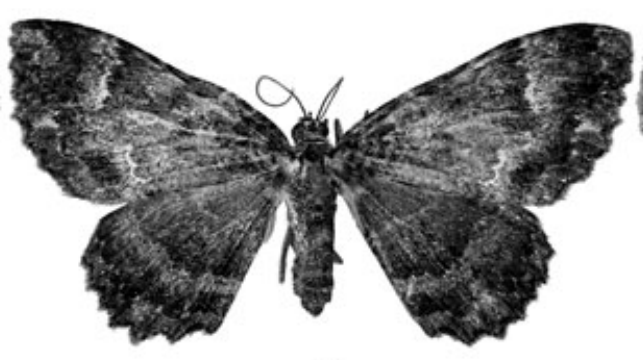

5

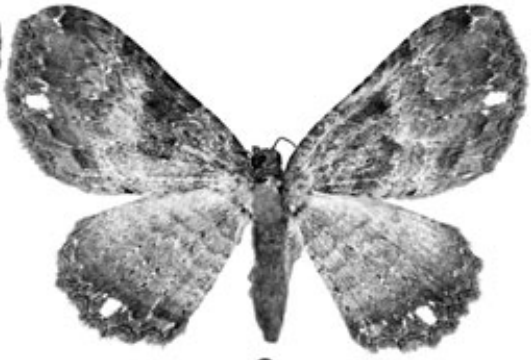

6
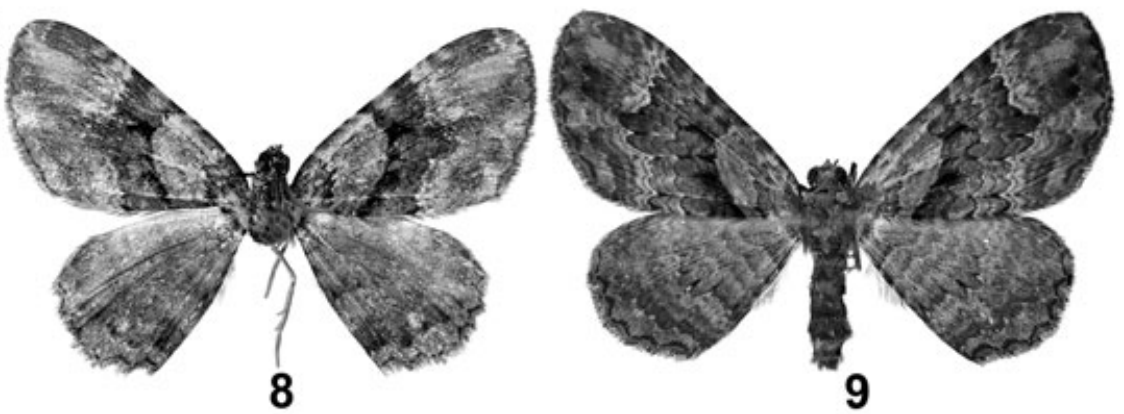

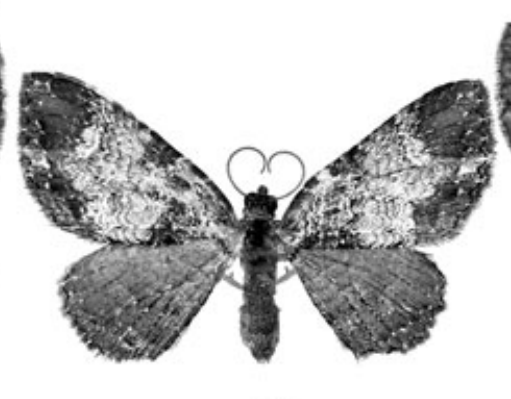

11

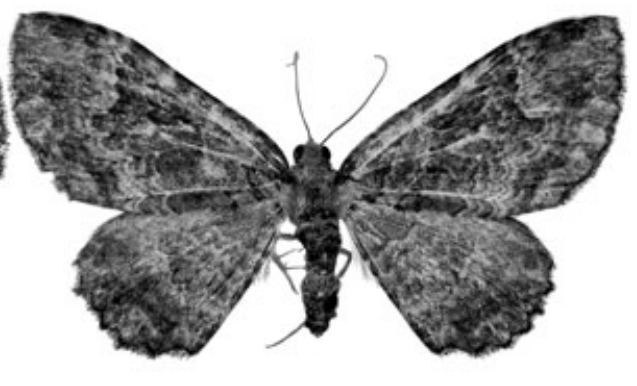

12

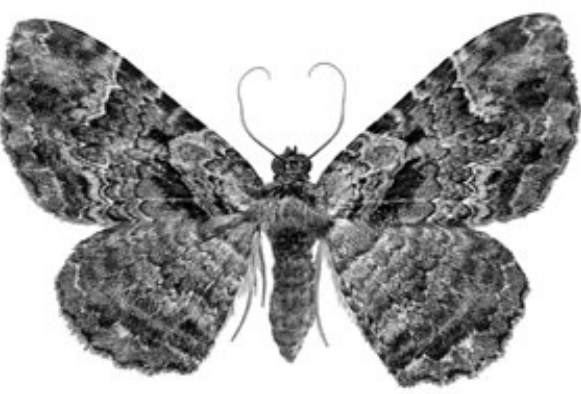

14

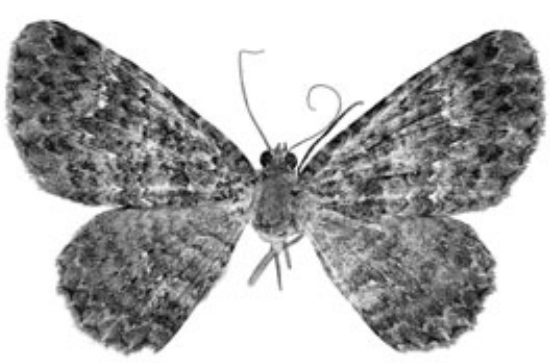

15

Figs 1-15. Scotocyma spp., wings above: (1-3,11) S. albinotata: (1,3) males; $\quad(\mathbf{2}, \mathbf{1 1})$ females; $\quad(\mathbf{4 , 6})$ S. legalis: $\quad(\mathbf{4})$ male $\quad(\mathbf{6})$ female; (5,7) S. samoensis: (5) female, (7) male; (8) S. asiatica male; (9,12) S. sumatrensis: (9) male; (12) female; (10) S. scotopepla male; (13,15) S. manusensis: (13) male; (15) female; (14) S. longiuncus male. Scale bar $10 \mathrm{~mm}$. 


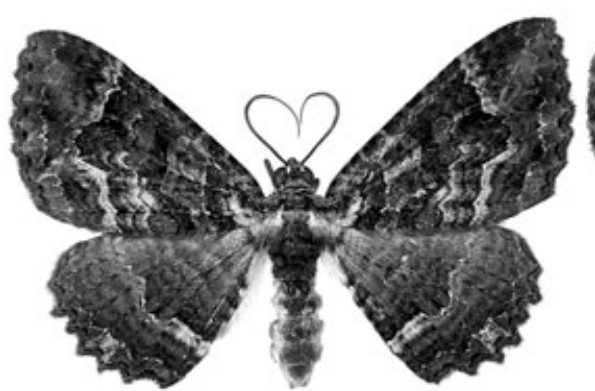

16

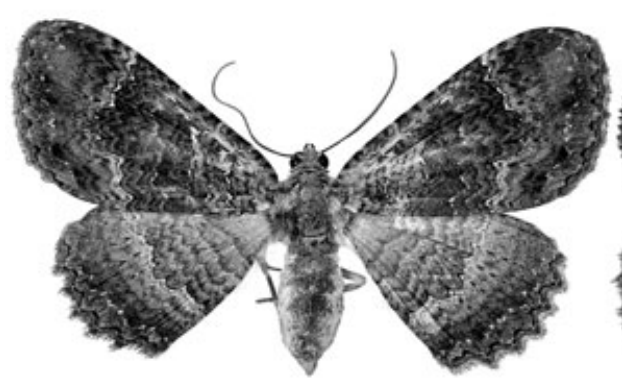

19

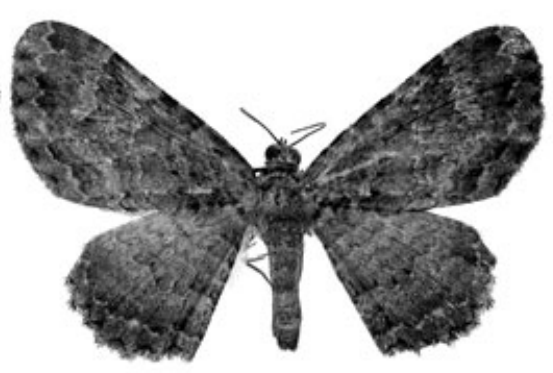

17

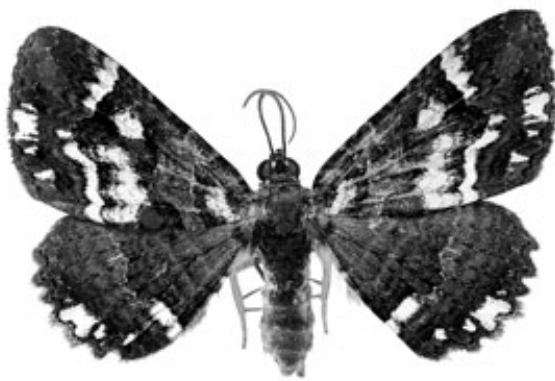

18

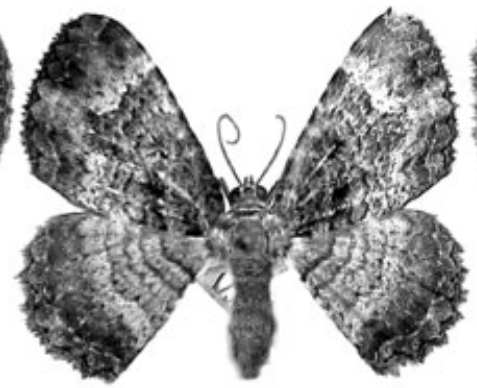

20

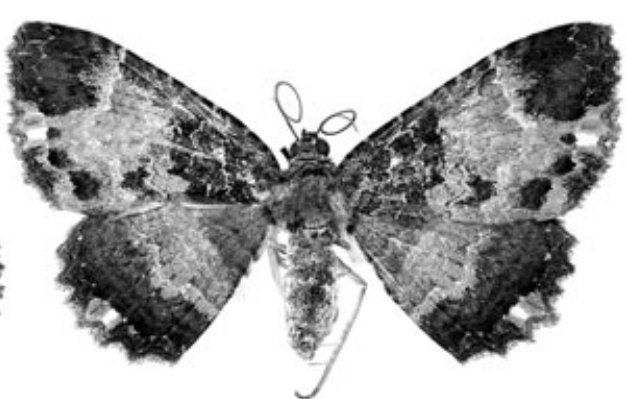

21

Figs 16-21. Scotocyma spp., wings above: (16,18,19,21) S. miscix:

$(\mathbf{1 6 , 1 8 )}$ males;

$(\mathbf{1 9 , 2 1 )}$ females;

(17) S. rutilimixta

female; (20) S. mimula female. Scale bar $10 \mathrm{~mm}$

4

Forewing underneath with median band rather indistinct, edged with whitish band, broadly interrupted medially or sometimes indistinct. Labial palpus without distinct rings of whitish scales (Figs 22,23,32)

\section{5} Forewing underneath with median band distinct, edged with whitish band not broadly interrupted medially, distinct. Labial palpus with distinct rings of whitish scales (Figs 24-30) 6 Palpus without or with very few fuscous-brown scales. Forewing underneath with median band edged with thin, whitish band, consisting of separate, wavy lines (Figs 1-3,11,22,23)............... S. albinotata (Walker)

- $\quad$ Palpus speckled with fuscous-brown. Forewing underneath with median band edged with thick, whitish band, rather evenly coloured (Figs 4,6,32) S. legalis (Warren) Forewing underneath with median band forming a tooth-like medial projection outwards. Hind wing underneath with a similar but slightly broader projection (Figs 9,12,25,26). S. sumatrensis sp. $\mathrm{n}$.

- $\quad$ Forewing underneath with median band forming a triangular medial projection outwards. Hind wing underneath with median band forming an indistinct rounded projection (Figs 24,27-30) ...... 7

7 Forewing underneath mainly pale brownish, with a few yellow scales in basal half. Hind wing underneath with postmedian brown band relatively thin, slightly thicker than the whitish band (Figs 17,24).....
$-$

Forewing underneath mainly yellowish in basal half. Hind wing underneath with postmedian brown band thick, double to more than 3 times width of the whitish band (Figs 27-30)..

8

Forewing above with basal band not lighter than the median band in both sexes. Wings above with sharp, thin zig-zag lines at the termen and in the postmedial area. Hind wing underneath with whitish band thin, about one-fourth of width of the postmedian brown band (Figs 13,15,29). S. manusensis Prout

- $\quad$ Forewing above with basal band much lighter than the median band in males (females unknown). Wings above without sharp, thin zig-zag lines but with fine wavy lines at the termen. Hind wing underneath with whitish band thick, at least one-third of width of the postmedian brown band (Figs 27,28,30)............... 9

9 Face with whitish medial triangular spot. Hind wing above mainly light brown in basal half in females (males unknown). Forewing underneath with median brown band not curved, forming an obtuse-angled projection outwards (Figs 20,30) .

S. mimula (Warren)

- $\quad$ Face without whitish medial triangular spot. Hind wing above brown to dark brown in basal half. Forewing underneath with median brown band curved, forming an almost right-angled projection outwards (Figs 27,28) . 10

I0 Forewing underneath with large, white, somewhat rectangular spot at the hind angle of termen. Hind wing underneath with median brown band thin, dis- 


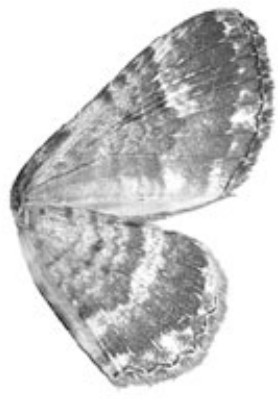

22

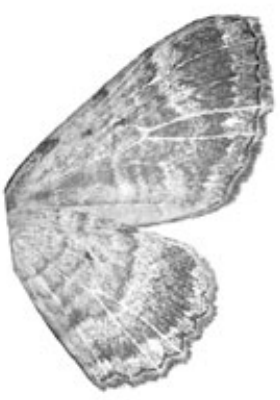

23

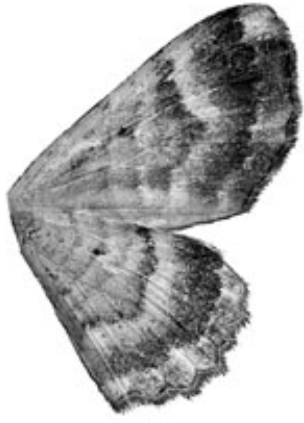

24

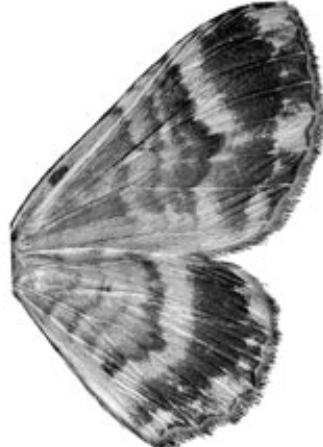

25

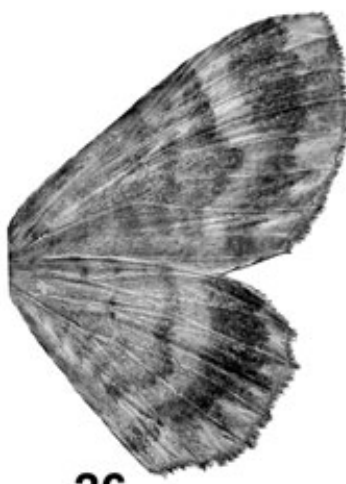

26

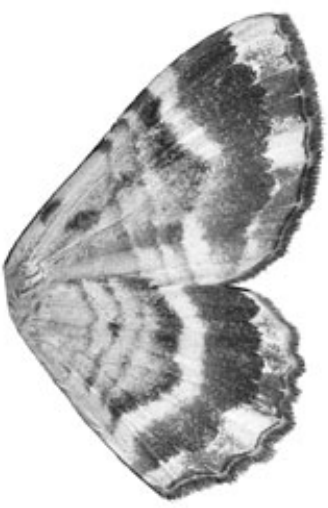

27

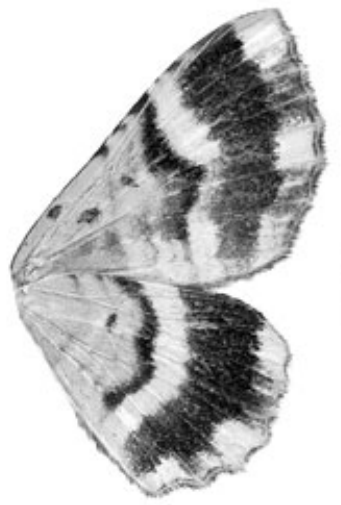

28

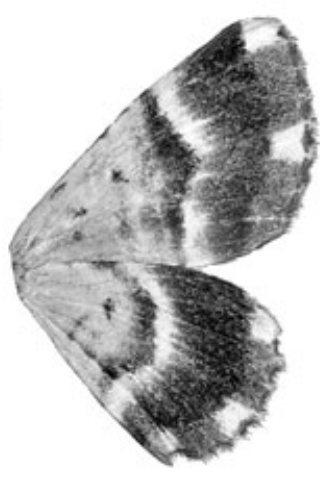

29

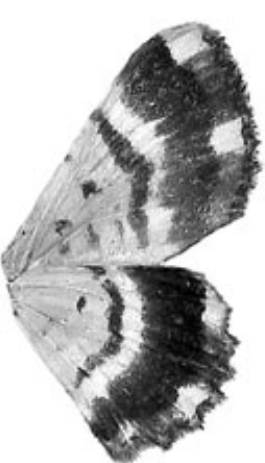

30

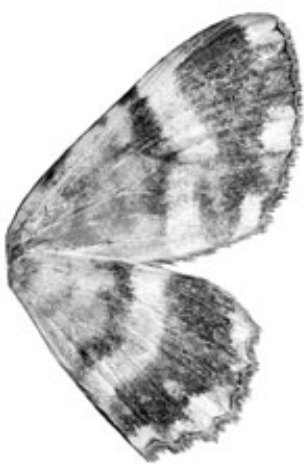

31

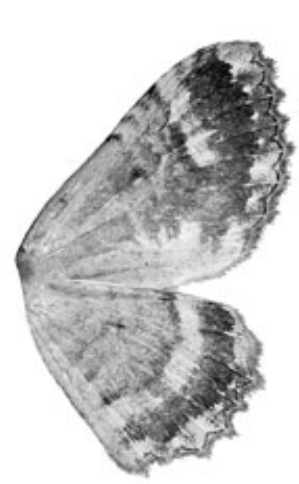

32

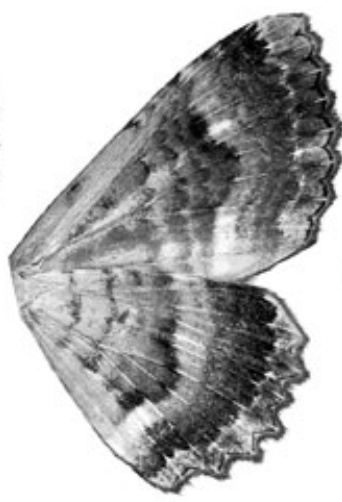

33

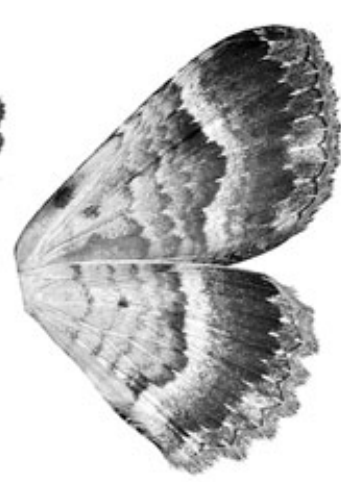

34

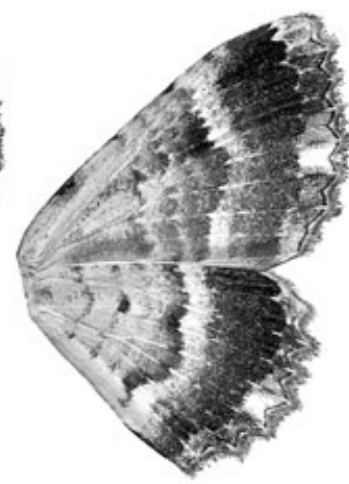

35

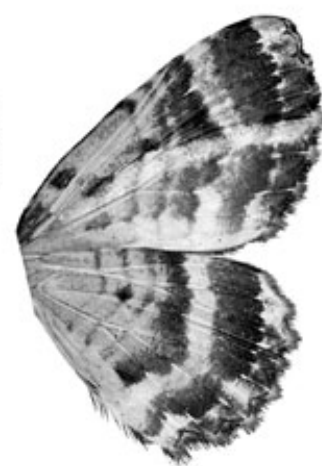

36

Figs 22-36. Scotocyma spp., wings underneath: (22,23) S. albinotata males; (24) S. rutilimixta female; (25,26) S. sumatrensis: (25) male; (26) female; (27) S. scotopepla male; (28) S. longiuncus male; (29) S. manusensis female; (30) S. mimula female; (31) S. asiatica male; (32) S. legalis male; (33-35) S. miscix: (33) male; (34,35) females; (36) S. samoensis male. Scale bar $10 \mathrm{~mm}$.

tinct, with white band thick, about a half of width of postmedian brown band (Figs 14,28)

S. longiuncus sp. n.

- $\quad$ Forewing underneath without large, white, rectangular spot at the hind angle of termen, only with some white scales. Hind wing underneath with median brown band thick, rather indistinct, with white band relatively thin, less than a half of width of postmedian brown band (Figs 10,27)...... S. scotopepla Prout

\section{Scotocyma albinotata (Walker)}

(Figs I-3, I I 22,23,38,49,50,59-62,66,7 I-73,74)

Scotosia albinotata Walker (1866): 1689.

Scotocyma albinotata (Walker): Turner (1904): 246. 


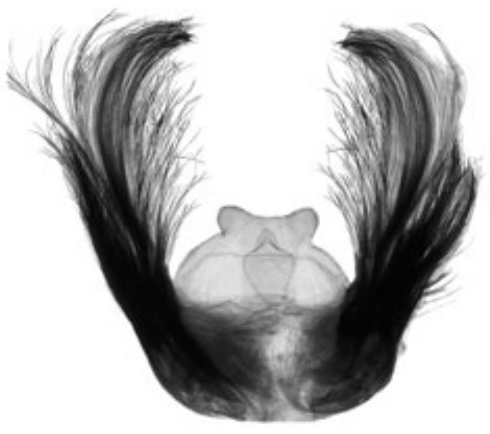

37

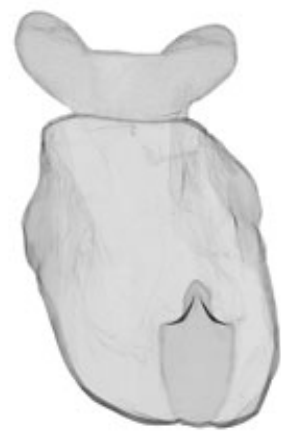

38

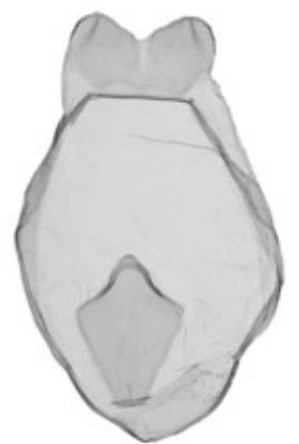

39

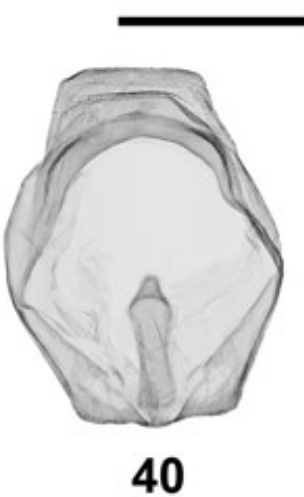

Figs 37-40. Scotocyma spp., coremata in males: (37) S. samoensis, hairs of coremata and sclerotised ring between the seventh and eighth segments; (38-40) sclerotised ring between the seventh and eighth segments: (38) S. albinotata; (39) S. manusensis; (40) S. miscix. Scale bar $1 \mathrm{~mm}$.

Xanthorhoe? platydesma Lower (1894): 79.

Scotocyma platydesma (Lower): Turner (1904): 246 (as syn. n.).

Scotocyma euryochra Turner (1922): 242 (syn. n.).

Scotocyma idioschema Turner (1922): 242 (syn. n.).

Scotocyma transfixa Turner (1931): 337 (syn. n.).

Scotocyma ischnophrica Turner (1932): 175 (syn. n.).

Types. Scotosia albinotata: Australia. Queensland. Holotype male, Moreton Bay, Mr Diggle's coll. (BMNH) (examined).

Scotocyma euryochra: Australia. New South Wales. Holotype female, Toronto, nr Newcastle, coll. Goldfinch, iv. (AMSA) (examined).

Scotocyma idioschema: Australia. Queensland. Syntypes: three females, Kuranda, coll. Lyell, xi. (DEMV); Evelyn Scrub, nr Herberton, F.P. Dodd, x.1910 (ANIC); Brisbane, [AJT], 4.i.1922 (ANIC) (examined).

Scotocyma ischnophrica: Australia. Queensland. Holotype female, Mt Tamborine, [AJT], 28.i.1932 (ANIC) (examined). Scotocyma transfixa: Australia. Queensland. Holotype female, [Lamington] N.P. (1000 m), W.B. Barnard, 26.ii.1929 (QM); Paratype female, Jandowae, nr Dalby, [W.B. Barnard], 1926 (ANIC) (examined).

Other material examined. Australia. Queensland. One male, Evelyn Scrub, F.P. Dodd, i.1911 (ANIC); 1 female, [Clermont], collector and date missing (BMNH); 1 female, Dawson distr., collector unknown, 19.xii.1909 (BMNH); 1 male, Bunya Mts N.P., O. Schmidt, 27-28.xi.1998 (OSPC); 1 male, Montville, [AJT], 15.iii.1920 (ANIC); 4 males, 10 females, Brisbane, [AJT] or F.P. Dodd or IFBC, 1900, 20.iv.1912, 25.v.1914, 4.vi.1921, 28-29.vi.1932, 24.iii.1940, 13.xi.1941, 26.i.1941, or date missing (ANIC, BMNH); 1 male, Toowoomba, IFBC, 23.xii.1938 (ANIC); 3 males, 2 females, [Lamington] N.P., [AJT], 24-28.xii.1922 (ANIC). New South Wales. 2 males, 2 females, Tooloom, IFBC, 26.iii.1958 (ANIC), IFBC \& M.S. Upton, 30.x.1961 (ANIC); 4 males, 1 female, Rous, [Richmond River], [VJR] or collector missing, iv.1924, xii.1924, viii.1925, date missing (ANIC, DEMV); 1 female, Narrabri, IFBC, 5.ix.1958 (ANIC); 1 male, 1 female, Ebor Scrub, LHMR, 20-29.i.1946 (ANIC); 7 males,
14 females, Narara, LHMR, 3.xi.1926, 13.ii.1941, 20.iii.1944, 15.vi.1945, 12.x.-21.xii.1945, 13.viii.1946, 1.i.1947, 1116.i.1949, 1.v.1949, 24.i.-16.ii.1950, 9.ii.1960 (ANIC); 4 males, 8 females, Sydney (Manly), D. Herbison-Evans, v.1976, viii.1978, 28.viii.1983, iii.1984, date missing (MMUS); 1 male, 1 female, Mt Keira, IFBC \& M.S. Upton, 15.xi.1960 (ANIC), VJR, 29.xi.1965 (ANIC); 1 male, locality and collector missing, 19.x.1923 (ANIC); 1 male, 1 female, Wollongong, VJR, 25.iii.1962, 22.xii.1965 (ANIC).

Description. Adult (Figs 1-3,11,22,23). Face brown scaled, with a few paler scales at base of antennae. Labial palpus brown, speckled with whitish scales. Forefemur anteriorly with brownish and some shining, pale yellowish scales. Wing expanse 27-36 mm. Forewing above ochreous-brown to dark brown, with median band usually darker, sometimes edged with white lines or extensive white or whitish blotching, sometimes with thin, white lines along the veins and/or with a large, oval, reddish-brown, spot in the middle of the wing, sometimes pattern indistinct, underneath with median band edged with whitish band consisting of separate, wavy lines, seldom indistinct, often with a small medial whitish spot at the termen; costa slightly curved distally, apex slightly rounded. Hind wing above usually slightly paler, with wavy median and posterior lines, often with white or whitish medial spot near termen, sometimes with white lines along the veins, underneath similar to the forewing but with whitish band broader, not interrupted medially.

Male genitalia (Figs 49,50). Uncus broadening and rounded distally, with a few small lateral teeth; tegumen at base with elongated, sclerotised, serrated lateral arms; valva narrowed medially, with costa weakly sclerotised, twisted at base, with medial, rounded, finely setose prominence; vunculum Ushaped; calcar medium-sized, with apical hook turned down, with hairs in its distal part; hood-shaped membrane with medium-sized, rounded lateral patches of hairs; aedeagus with a medial patch of weak scobination in vesica.

Female genitalia (Figs 59-62,66). Antrum heavily sclerotised, with a few longitudinal folds, trefoil in diameter; ductus bursae short, with an indistinct proximal ring of sclerotisation; corpus 


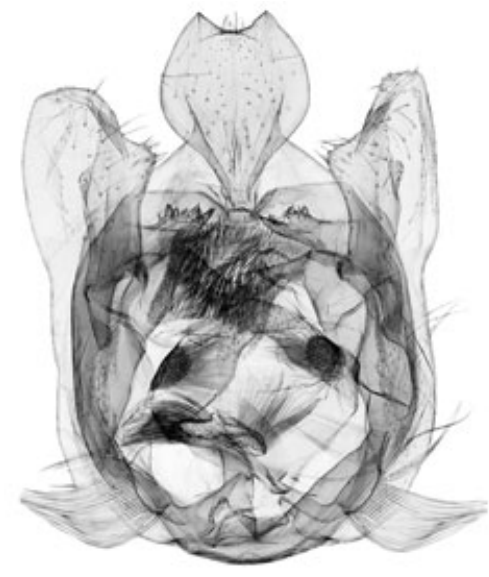

41

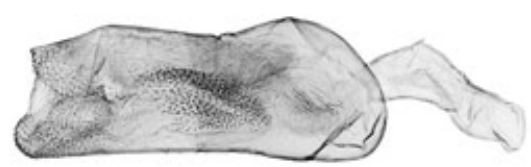

42

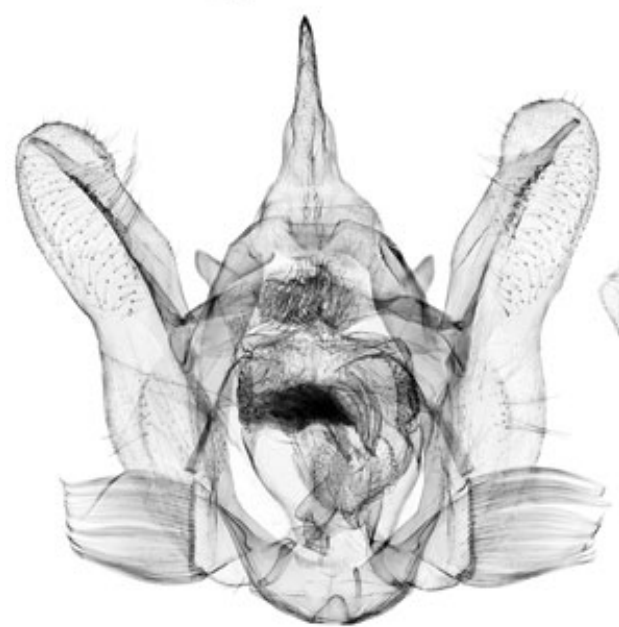

47

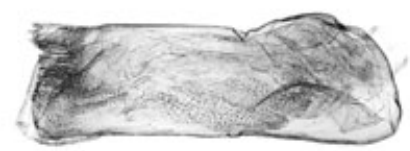

48
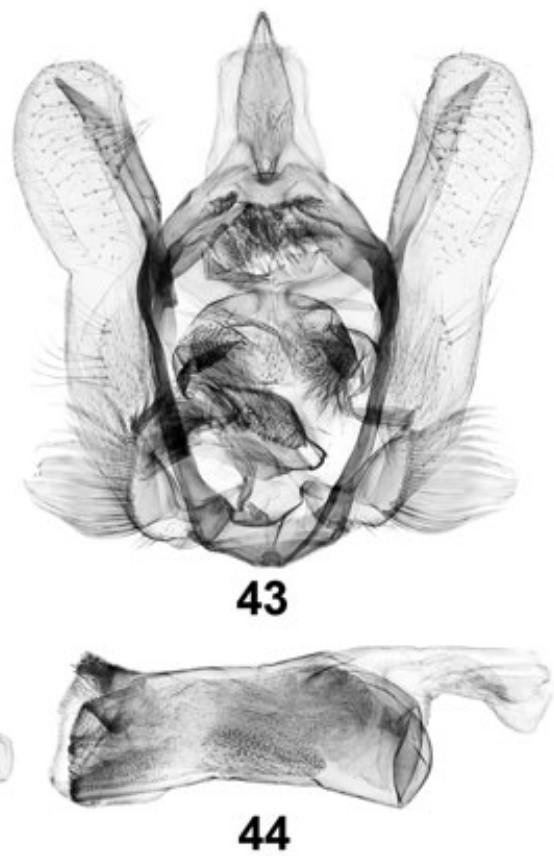

44
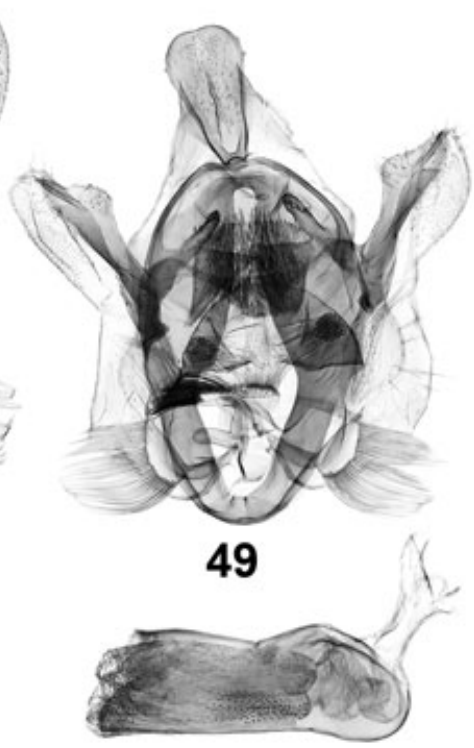

50

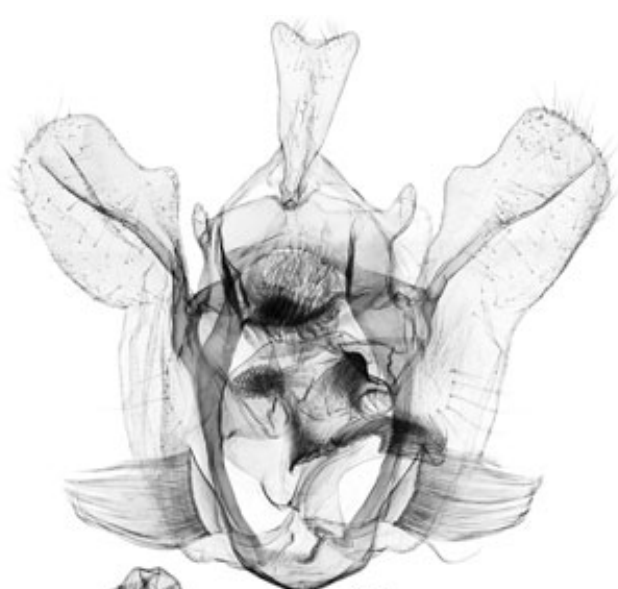

45

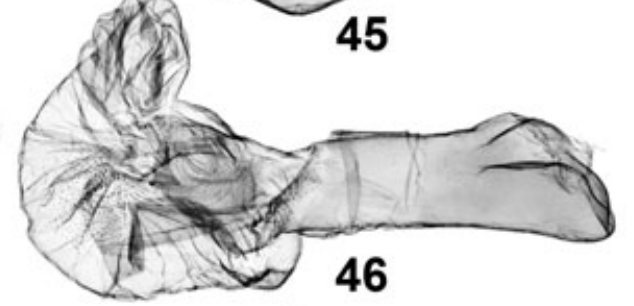

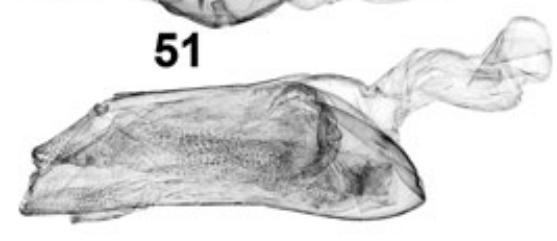

52

Figs 41-52. Scotocyma spp., male genitalia: (41,43,45,47,49,51) armature; $(\mathbf{4 2}, \mathbf{4 4 , 4 6 , 4 8 , 5 0 , 5 2 )}$ aedeagus; (41,42) S. legalis; $\quad(\mathbf{4 3 , 4 4 )}$ S. scotopepla; $\quad(\mathbf{4 5 , 4 6 )}$ S. asiatica; $\quad(\mathbf{4 7 , 4 8 )}$ S. manusensis; $\quad(\mathbf{4 9 , 5 0 ) ~ S . ~ a l b i n o t a t a ; ~} \quad(\mathbf{5 1 , 5 2 )}$ S. longiuncus. Scale bar $1 \mathrm{~mm}$.

bursae oval, with dorsal, relatively large, somewhat triangularshaped (S-shaped from side view), folded, thorny patch of sclerotisation close to the ductus bursae, with diverticulum longer and narrower than corpus bursae, elongate drop-shaped, weakly membranous; signum a relatively small, broad, dropshaped patch of small spicules.

Larva (Figs 71-73). Last-instar larva relatively stout, about $30 \mathrm{~mm}$ in length. Head brown, with dark brown triangular medial spot. Body greyish-brown, smooth, with darker brown- ish zigzag pattern along the sides (D Herbison-Evans pers. comm. 2002).

Biology. Larvae were found feeding on Coprosma repens (Rubiaceae) (D Herbison-Evans pers. comm. 2002). The plant is native to New Zealand and widespread in the Pacific Basin.

Habitat. Subtropical rainforest, at altitudes of 500-1200 m. Distribution (Fig. 74). Eastern Australia (Queensland, New South Wales). 


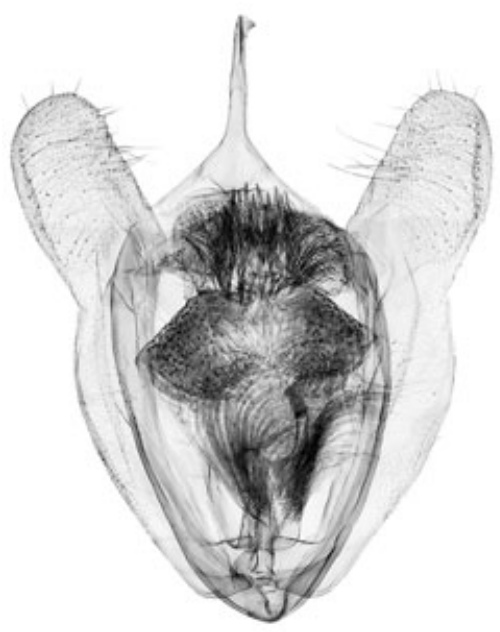

53

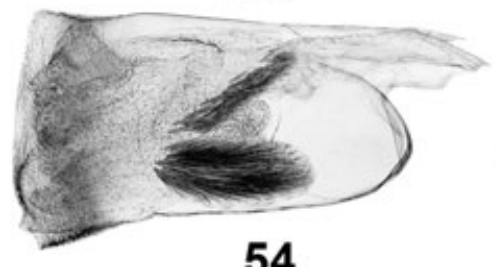

54

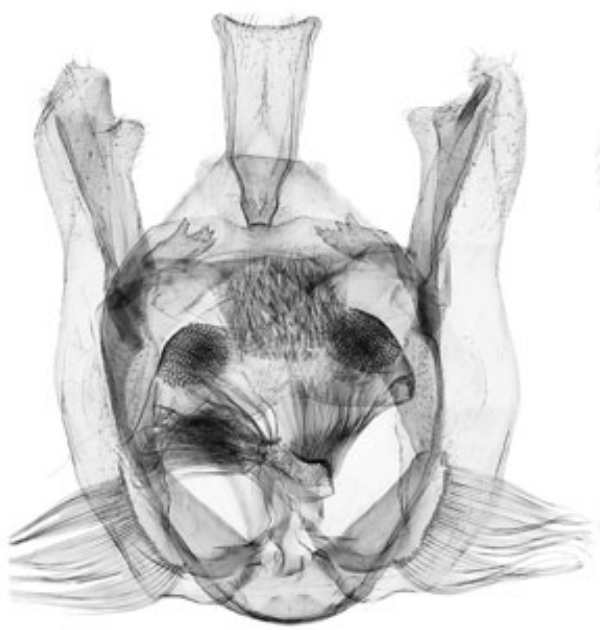

55

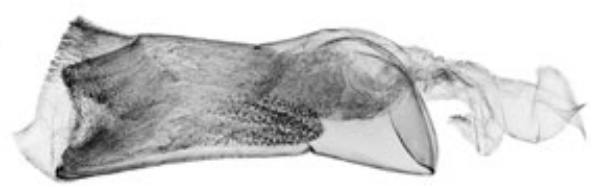

56

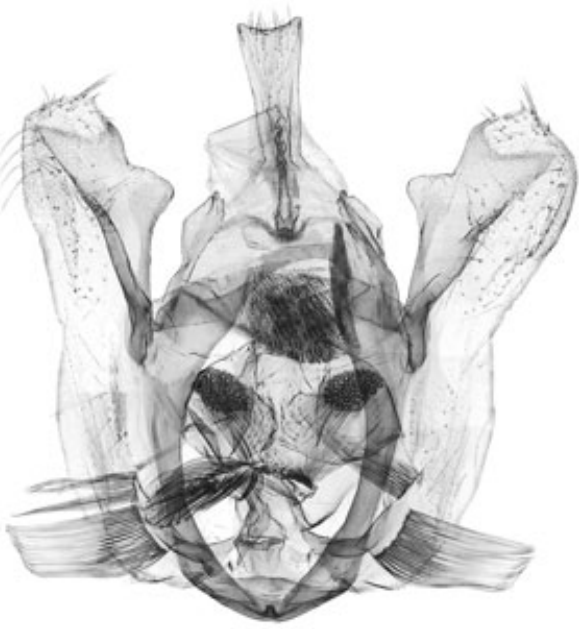

57

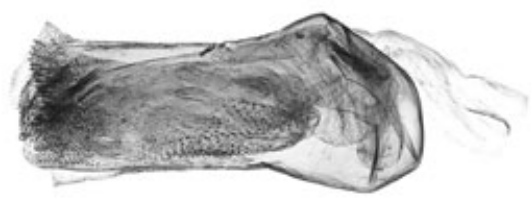

58

Figs 53-58. Scotocyma spp., male genitalia: $\mathbf{( 5 3 , 5 5 , 5 7 )}$ armature; $\quad(\mathbf{5 4 , 5 6 , 5 8 )}$ aedeagus; $(\mathbf{5 3 , 5 4 )} \quad$ S. miscix; $\quad(\mathbf{5 5}, \mathbf{5 6})$ S. samoensis; $\quad(\mathbf{5 7 , 5 8 )}$ S. sumatrensis. Scale bar $1 \mathrm{~mm}$.

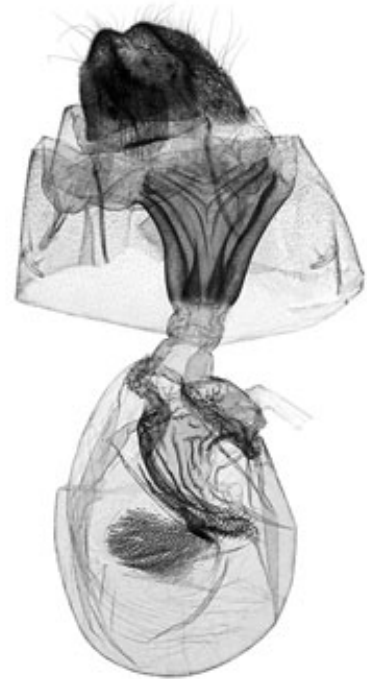

59

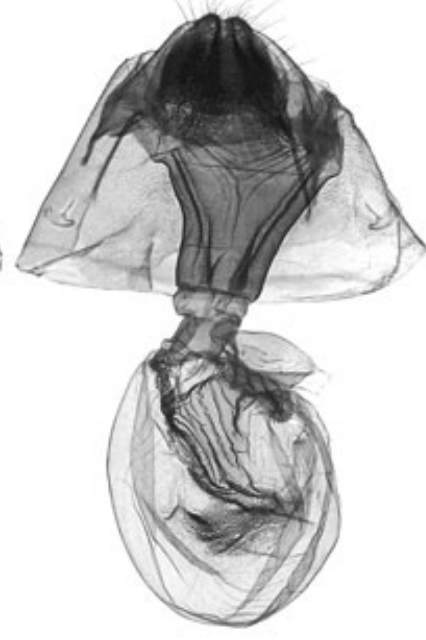

60

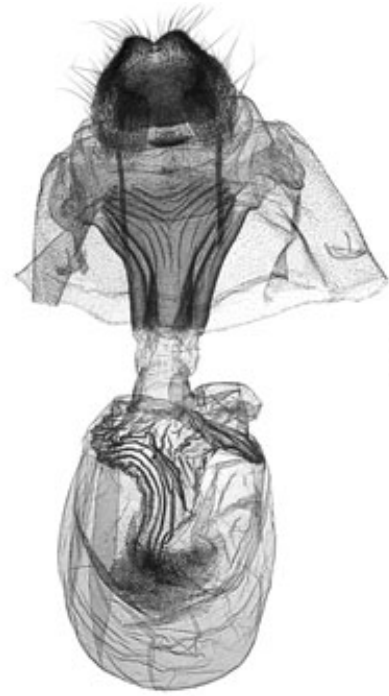

61

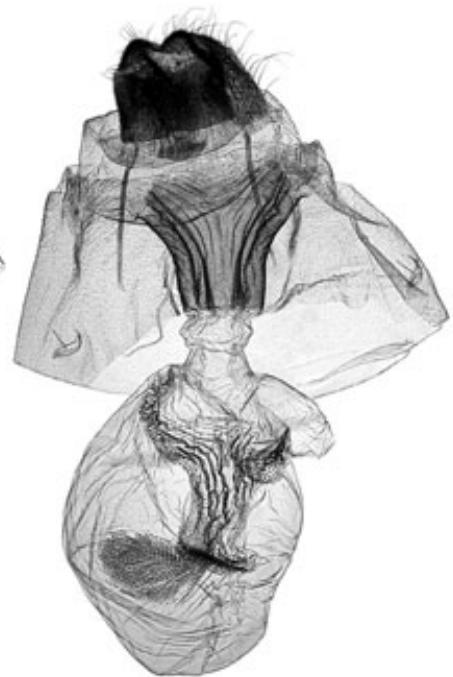

62

Figs 59-62. Scotocyma albinotata, female genitalia: (59) S. euryochra (syn. n.), holotype (AMSA); (60) S. idioschema (syn. n.), syntype (ANIC); (61) S. ischnophrica (syn. n.), holotype (ANIC); (62) S. transfixa (syn. n.), holotype (QM). Scale bar 1 mm.

Remarks. Examination of the type specimens of $S$. euryochra, S. idioschema, S. ischnophrica and S. transfixa showed that they all belong to one species and identical to S. albinotata (Figs 59-62,66). The original descriptions of those species were mainly based on differences of the wing pattern, which is very variable. The genital structures have not been compared before.
Scotocyma legalis (Warren)

(Figs 4,6,32,4I,42,67,74)

Coenocalpe? legalis Warren (1896): 384.

Scotocyma albinotata legalis (Warren): Prout (1940): 293 (as subspecies).

Scotocyma legalis (Warren): Holloway (1979): 319. 

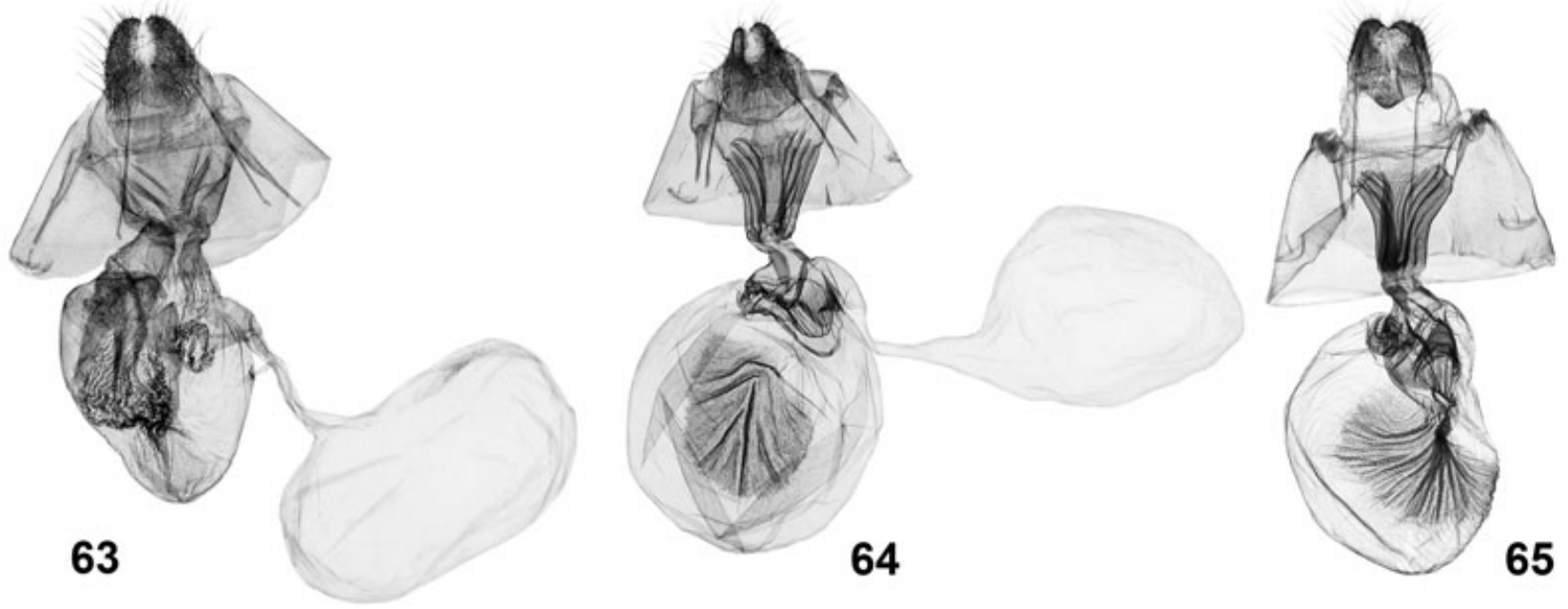

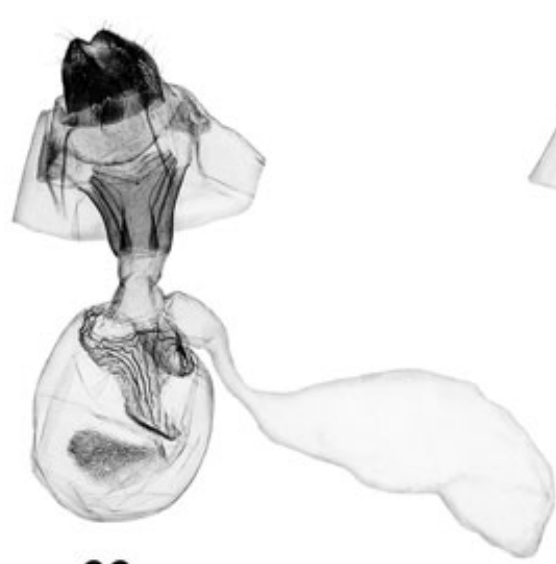

66

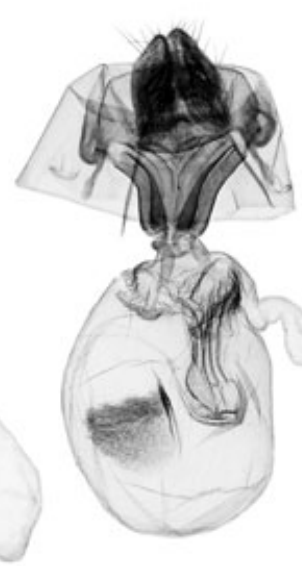

.

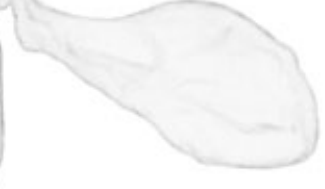

67

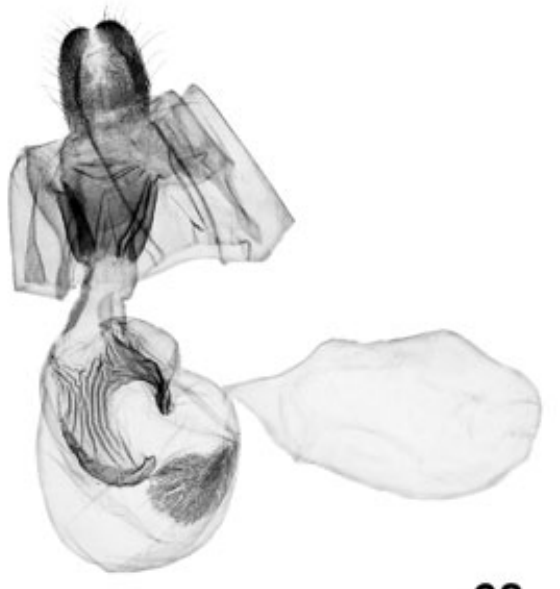

68

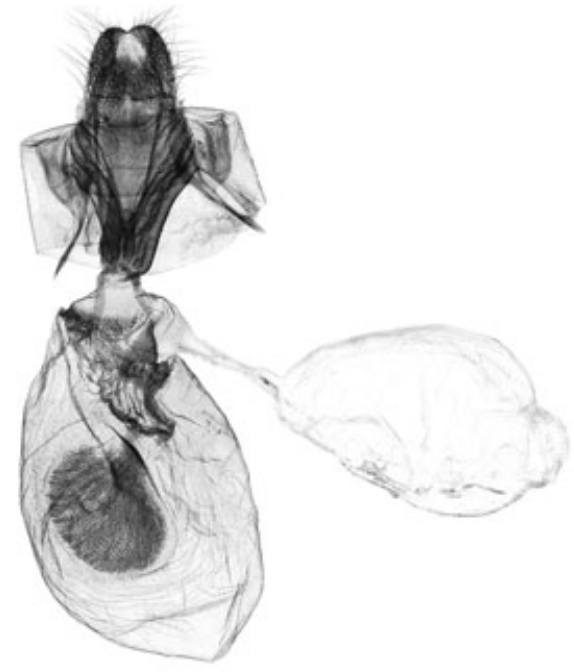

69

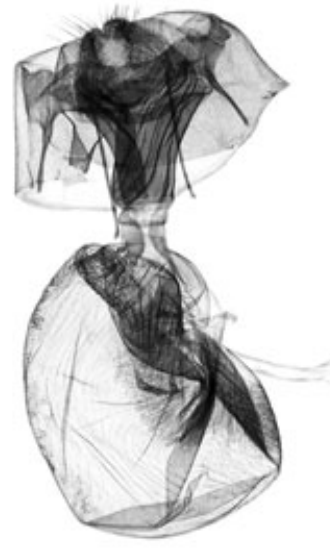

70

Figs 63-70. Scotocyma spp., female genitalia: (63) S. miscix; $\quad$ (64) S. rutilimixta; (65) S. mimula; (66) S. albinotata; (67) S. legalis; (68) S. samoensis; (69) S. sumatrensis; (70) S. manusensis. Scale bar $1 \mathrm{~mm}$. 

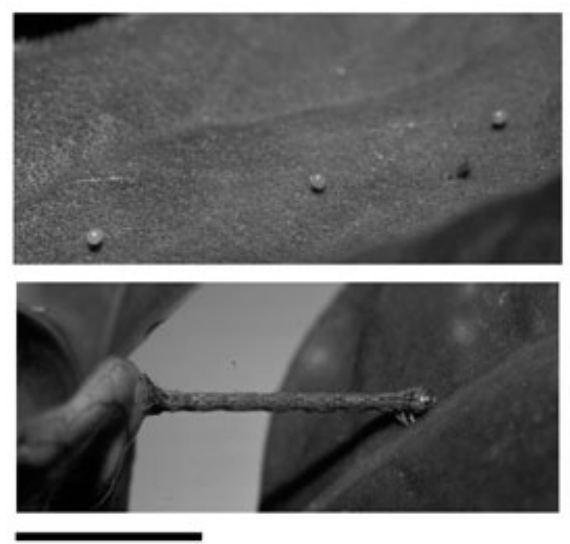

71

72

Figs 71-73. Scotocyma albinotata, immature stages: $10 \mathrm{~mm}$.

Types. New Caleonia, Loyalty Islands. Lifu. Holotype female (BMNH) (examined).

Other material examined. New Caledonia. One male, Col des Roussettes, JDH, 21.vii.1971; 2 males, Mt Krapé, JDH, 22.vii.1971; 1 male, Mt Koghis, JDH, 21.viii.1971 (all $\mathrm{BMNH}$ )

Description (Figs 4,6,32). Face dark brown scaled medially, with light brown and reddish scales at palpi and base of antennae. Labial palpus covered with dark brown, fuscous-brown and ochreous scales, with a fine ring of whitish scales at base of medial palpal segment. Forefemur anteriorly dark brownish, with brown and a few whitish scales. Wing expanse 34$37 \mathrm{~mm}$. Forewing above brown to ochreous- and greyishbrown, with median band darker, at hind margin indistinct, with basal band in males paler than the rest of the wing, sometimes with white medial dot at the termen, underneath mainly greyish-brown, with yellowish scales only at costa, with a few very fine brownish lines and a discal brownish dot, with median band edged with rather broad, wavy whitish band broadly interrupted medially, with rather small apical and medial white square spots at the termen; costa strongly curved distally, apex slightly rounded. Hind wing above usually of the same colour as forewing, with wavy, ochreous and dark brown median and posterior lines, underneath coloured and patterned like forewing, but with median band edged with broad whitish band not interrupted medially.

Male genitalia (Figs 41,42). Uncus relatively short, almost as broad as long, broadest in the middle, with apical edge concave; tegumen at base with broadened, sclerotised, roughly serrated lateral arms; valva rather short, slightly narrowed medially, with costa sclerotised, with medial, rounded, setose prominence; vinculum broad, rounded; calcar medium-sized, with apical hook turned down, with thick hairs in its distal part; hood-shaped membrane with large, rounded lateral patches of thick hairs; aedeagus with a medial patch of scobination in vesica.

Female genitalia (Fig. 67). Antrum heavily sclerotised, broader than in S. albinotata, with a few longitudinal folds; ductus bursae very short; corpus bursae oval, with dorsal elon- gate tongue-shaped, folded patch of sclerotisation, with fine thorns at its left side, with diverticulum slightly smaller than corpus bursae, drop-shaped, weakly membranous; signum a medium-sized, drop-shaped patch of small inwardly directed spicules.

Habitat. Primary rainforest on the boundary of ultramafic and sedimentary rocks, podocarpus forest, rich rainforest on ultramafic rock, at the altitudes 340-800 m (Holloway 1979).

Distribution (Fig. 74). Loyalty Islands (Lifu), New Caledonia.

\section{Scotocyma samoensis sp. $\mathbf{n}$.} (Figs 5,7,36,37,55,56,68,74)

Types. Western Samoa. Upolu Island. Holotype male, Lake Lanoto, 600 m, J.G. Hateley, 5-6.viii.1986 (BMNH). Paratype: 1 female, Mt Vaea, 460 m, G.S. Robinson, 26.viii.1974 (BMNH).

Description. Face deep blackish-brown scaled, with a few light brown and pale ochreous scales at base of antennae and at palpi. Labial palpus blackish-brown, with a ring of pale ochreous scales at base of medial palpal segment. Forefemur anteriorly dark brown, with shining, pale yellowish scales. Wing expanse 34-39 mm. Forewing above blackish-brown to greyish- and reddish-brown, with median band darker, in female less distinct, almost without reddish-brown, edged with wavy greyish- and ochreous-brown lines, in male with pale yellowish medial strip from basis to the termen, which could be an artifact and not present in other specimens, underneath yellowish in basal half, with costal and medial brownish spots, and brownish wavy bands, in female less distinct, with median band forming medial rounded projection outwards, edged with whitish band, in male with pale medial strip representing the yellowish strip of upperside, with small apical and medial pale yellowish square spots at the termen; costa slightly curved distally, apex slightly pointed. Hind wing above of the same colour as forewing, with wavy brown, greyish, and blackish median and posterior lines, but without the medial strip from basis to the termen, underneath coloured and patterned similar 

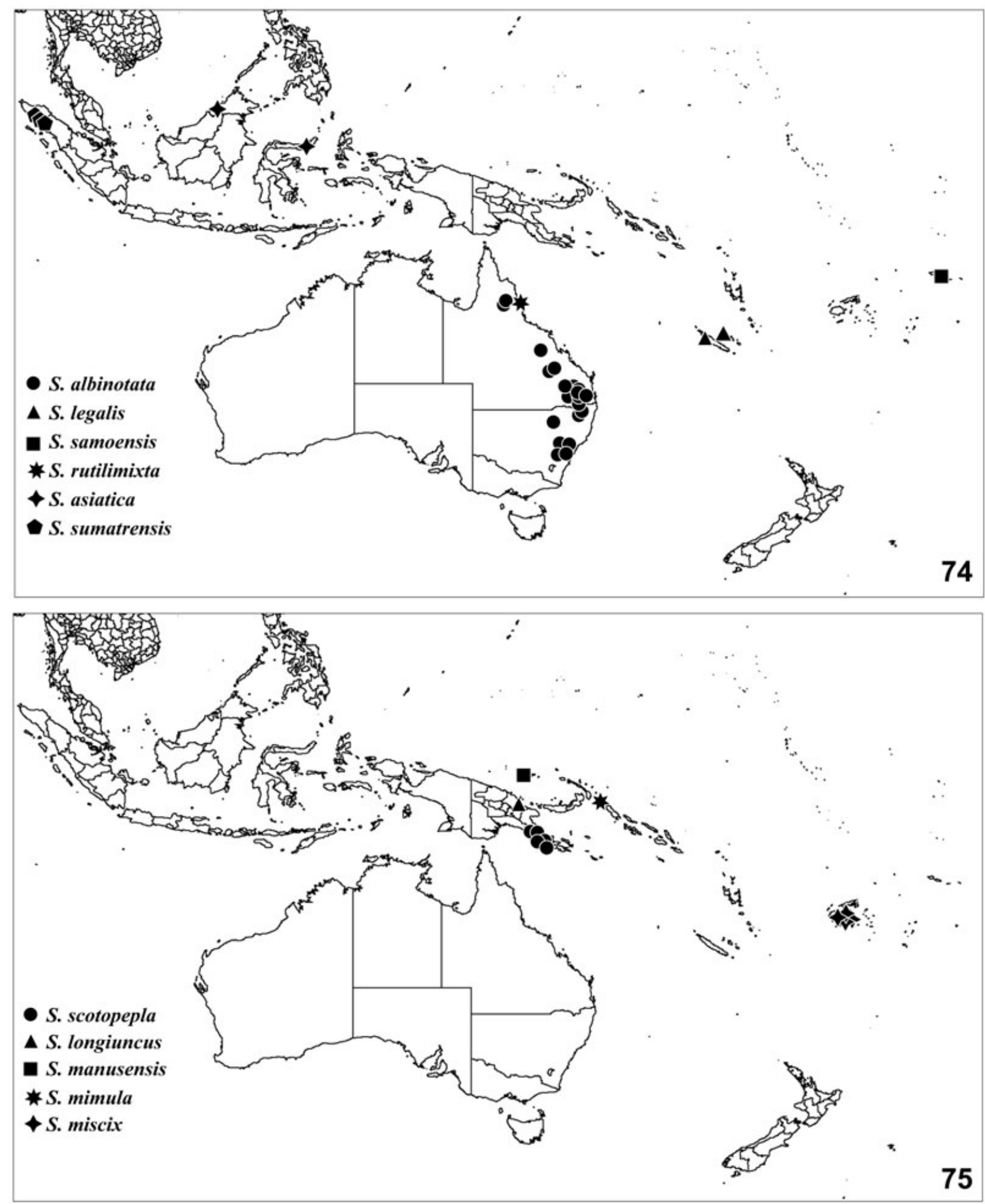

Figs 74,75. Distribution maps of Scotocyma spp. (74) S. albinotata, S. legalis, S. samoensis, S. rutilimixta, S. asiatica, S. sumatrensis; (75) S. scotopepla, S. longiuncus, S. manusensis, S. mimula, S. miscix.

to forewing (Figs 5,7,36). Coremata pockets in males with blackish-brown hair tufts (Fig. 37).

Male genitalia (Figs 55,56). Uncus somewhat elongate trapeziform, broadest apically, with apical edge weakly concave; tegumen at base with broadened, sclerotised, roughly serrated lateral arms which are slightly shorter than in S. legalis; valva longer than in S. legalis, slightly narrowed medially, with costa sclerotised, with medial, rounded, finely setose promi- 
nence; vinculum rather broad, U-shaped; calcar large, with apical hook turned down, with dark, thick, long hairs in its distal part; hood-shaped membrane with large, rounded lateral patches of very thick hairs; aedeagus with a medial patch of rough scobination in vesica.

Female genitalia (Fig. 68). Antrum similar to S. miscix but heavily sclerotised, with a few oblique-longitudinal folds; ductus bursae longer and broader than in S. albinotata, membranous; corpus bursae more or less oval, with dorsal, C-shaped, folded, laterally thorny patch of sclerotisation close to the ductus bursae, with diverticulum about as large as corpus bursae, elongate drop-shaped, weakly membranous; signum a mediumsized, drop-shaped patch of small inwardly directed spicules. Habitat. Primary forest, at altitudes of 460-600 m.

Distribution (Fig. 74). Western Samoa (Upolu).

Etymology. The species name refers to its distribution within Samoan islands.

\section{Scotocyma rutilimixta sp. $\mathrm{n}$. (Figs $\mid 7,24,64,74)$}

Type. Australia. Queensland. Holotype female, Cairns distr., F.P. Dodd, date missing, coll. Lyell (DEMV).

Description (Figs 17,24). Face brown, with ochreous scales. Labial palpus brown, with some ochreous scales. Forefemur anteriorly with brownish and shining, whitish scales. Wing expanse $35 \mathrm{~mm}$. Forewing above rusty-brown to light brown, with median band rather indistinct, with postmedian wavy reddish-brown band, underneath without yellow scales, with small medial brownish spot, with median band forming medial triangular projection outwards, edged with whitish band, not interrupted medially, with medium-sized apical and medial whitish square spots at the termen; costa curved distally, apex slightly rounded. Hind wing above of the same colour as forewing, with wavy, brown and dark ochreous median and posterior lines, without white medial spot near termen, underneath coloured and patterned similar to forewing, but with median band forming rounded projection outwards, with brown postmedial band not narrowing towards the hind margin, and with additional whitish square spot at the anal angle. Male unknown.

Female genitalia (Fig. 64). Antrum sclerotised, longitudinally folded; ductus bursae short, sclerotised proximally; corpus bursae spherical, with dorsal, relatively small, tongue-shaped patch of sclerotisation, with longitudinal folds in its medial area, with rows of small thorns close to the ductus, with diverticulum slightly smaller than corpus bursae, drop-shaped, membranous; signum a rather large, shell-shaped, softly folded patch of fine spicules.

Distribution (Fig. 74). Australia (northern Queensland: Cairns).

Etymology. The species name combines the Latin rutilus (reddish) and mixtim (mixed) and refers to the wing colouration.

\section{Scotocyma asiatica Holloway (Figs 8,3 I, 45, 46,74)}

Types. Brunei. Holotype male, Bukit Retak, 1618 m, [M.G. Allen], 14.ix.1979 (BMNH) (examined). Indonesia.
Sulawesi. Paratype male, Dumoga-Bone N.P., Site 15, Hill '1440', 1140 m, JDH, 6-8.viii.1985 (BMNH) (examined).

Description (Figs 8,31). Face dark brown scaled, with paleochreous scales at base of antennae. Labial palpus brown, speckled with dark brown scales, with distinct rings of whitish scales at base and distal end of medial palpal segment. Forefemur anteriorly whitish, with shining, pale yellowish and light brown scales along the sides. Wing expanse 35-36 mm. Forewing above brown to ochreous-brown, with median band relatively thin, darker, with basal band distinct, lighter brown, edged with blackish line, underneath yellowish-brown in basal half, with costal brown spots, with median band forming medial triangular projection outwards, edged with very broad whitish band not interrupted medially, with small apical and hind-marginal white spots, and a large medial white square spot at the termen; costa slightly curved distally, apex slightly rounded. Hind wing above of the same colour as forewing, with indistinct, broad, dark brownish median and posterior lines, underneath coloured and patterned similar to forewing. Male genitalia (Figs 45,46). Uncus rather elongate triangular, broadening distally; tegumen at base with short, weakly sclerotised, unserrated lateral arms; valva broad, slightly narrowed medially, with costal lobe broad, weakly sclerotised, slightly twisted at base, with broad, medial, not sclerotised, rounded prominence; vinculum U-shaped; calcar medium-sized, with large apical hook turned down, with hairs in its distal part; hood-shaped membrane with medium-sized, rounded lateral patches of hairs; aedeagus with a medial patch of very weak scobination in vesica.

Female unknown.

Habitat. Brunei: upper montane forest zone, at an altitude of 1620 m (Holloway 1997); Sulawesi: probably lower montane forest, at an altitude of $1140 \mathrm{~m}$ (JD Holloway pers. comm. 2004).

Distribution (Fig. 74). Brunei, Indonesia (Sulawesi).

\section{Scotocyma sumatrensis sp. $\mathbf{n}$. (Figs 9, I 2, 25, 26,57,58,69,74)}

Types. Indonesia. Sumatra. Holotype male, E of Lake Toba, 'Holzweg 4', 1150 m, E.W. Diehl, 7.iii.1993 (MSPC). Paratypes: 1 male, $30 \mathrm{~km}$ E Sidikalang (Dairi), $1800 \mathrm{~m}$, E.W. Diehl, 22.iii.1989 (MSPC); 1 female, $2^{\circ} 46^{\prime} \mathrm{N}, 98^{\circ} 58^{\prime} \mathrm{E}, 14 \mathrm{~km}$ NE Prapat (Simalungun), 'Holzweg 3', 1150 m, E.W. Diehl, 14.x.1984 (MSPC); 1 male, $2^{\circ} 46^{\prime} \mathrm{N}, 9^{\circ} 58^{\prime} \mathrm{E}$, nr Prapat, 'Holzweg 2', 1050 m, E.W. Diehl, 1.xii.1991 (ZSM).

Description (Figs 9,12,25,26). Face brown, with reddishbrown and ochreous scales. Labial palpus dark brown, speckled with brown scales, with distinct rings of whitish scales at base and distal end of medial palpal segment. Forefemur anteriorly shining, pale yellowish, with dark brown scales along the sides. Wing expanse $36-38 \mathrm{~mm}$. Forewing above brown to ochreous- and dark brown, with median band darker, edged with a thin ochreous line, with basal band distinct, brown to ochreous-brown, in female with greyish-brown scales, underneath yellowish-brown, with greyish scales in basal half, with thin greyish-brown lines and costal brown spots, with median 
band forming medial triangular projection outwards, wavy towards the costal and hind margins, edged with rather broad whitish band, not interrupted medially, with rather small apical and hind-marginal white spots and a large medial white square spot at the termen; costa slightly curved distally, apex slightly rounded. Hind wing above of the same colour as forewing, with wavy, ochreous and brown median and posterior lines, underneath coloured and patterned similar to forewing, with discal dot indistinct, but with median band forming wavy rounded projection outwards.

Male genitalia (Figs 57,58). Uncus rather elongate triangular, broadening distally, similar to $S$. asiatica but thinner; tegumen at base with rather short, moderately sclerotised, softly serrated lateral arms; valva broad, slightly narrowed medially, with costal lobe broad, stronger sclerotised than in S. asiatica, slightly twisted at base, with distinct, medial, somewhat triangular, sclerotised prominence, comb-like structures close to sacculus larger than in S. asiatica; vinculum U-shaped; calcar medium-sized, with large apical hook turned down, with thick hairs in its distal part; hood-shaped membrane with mediumsized, rounded lateral patches of hairs, thicker than in S. asiatica; aedeagus stronger sclerotised than in S. asiatica, with a medial patch of weak scobination in vesica.

Female genitalia (Fig. 69). Antrum heavily sclerotised, longitudinally folded; ductus bursae very short, distinctly sclerotised proximally; corpus bursae very large, somewhat egg-shaped, with fine rounded folds, with dorsal somewhat triangular-shaped, softly folded patch of rather heavy sclerotisation, similar to S. albinotata but smaller, and with short, scattered thorns close to the ductus, with diverticulum much smaller than corpus bursae, egg-shaped, weakly membranous; signum a moderate, rounded, asymmetrical patch of relatively thick, inwardly directed spicules.

Habitat. Mountain forest at altitudes of 1050-1800 m.

Distribution (Fig. 74). Indonesia (Sumatra).

Etymology. The species name refers to its distribution within Sumatra.

\section{Scotocyma scotopepla Prout stat. $\mathbf{n}$. (Figs I 0,27,43,44,75)}

Scotocyma albinotata scotopepla Prout (1940): 293.

Types. Papua New Guinea. Lectotype male, Kumusi River, [ASM], vi.1907 (BMNH); this specimen is here designated lectotype so as to fix and stabilise the current concept of the name and has been so labelled (examined). Paralectotypes: 1 male, Kumusi River, ASM, v.1907; 1 male, Upper Aroa River, [ASM], ii.1903; 2 males, Hydrographer Mts, [ASM], iii.v.1918; 1 male, Port Moresby, A. Goldie (all BMNH) (examined).

Other material examined (not a type). Papua New Guinea. One male, Wau, Morobe distr., J. \& M. Sedlacek, 3.iii.1965 (BPBM).

Description (Figs 10,27). Face blackish-brown scaled, with some brown and ochreous scales at base of antennae. Labial palpus brown to dark brown, with rings of whitish scales less distinct at base and more distinct at distal end of medial palpal segment. Forefemur anteriorly shining, pale yellowish, with brown scales along the sides. Abdomen apically blackishbrown. Wing expanse $35-40 \mathrm{~mm}$. Forewing above brown to ochreous- and reddish-brown, with median band darker, sometimes edged with a thin ochreous line, with basal band in males lighter than the rest of the wing, underneath yellowish in basal half, with thin brownish lines, with medial and costal brown spots, with median band forming medial triangular projection outwards, edged with distinct, rather broad whitish band not interrupted medially, thin at the lower side of the medial triangular projection, with large apical and medial white square spots at the termen; costa slightly curved distally, apex slightly rounded. Hind wing above usually of the same colour as forewing, with discal dot not prominent, with wavy, ochreous and dark brown median and posterior lines, underneath coloured and patterned similar to forewing, but with median band forming double rounded projection outwards.

Male genitalia (Figs 43,44). Uncus relatively short, lanceolate, with a very small hook distally; tegumen at base with weakly sclerotised, finely serrated lateral arms; valva with costa sclerotised, twisted at base, setose in its medial region, with an apically projecting point, with apices reaching well beyond the half height of uncus; vinculum U-shaped; calcar rather short, with large apical hook turned down, with thick hairs in its distal part; hood-shaped membrane with mediumsized, rounded lateral patches of hairs; aedeagus with a medial patch of weak scobination in vesica.

Female unknown.

Habitat. Rainforest, at altitudes of 760-1200 m.

Distribution (Fig. 75). Papua New Guinea.

Remarks. This species was described as a subspecies of $S$. albinotata with presumption that it could be a new species. Later it was listed as a subspecies (Holloway 1997; Scoble 1999). Adults of S. scotopepla differ from those of S. albinotata in their usually larger size and much brighter underside of wings, with yellow scales present, in the shape and length of uncus, in the size of comb-like structures, in the size and shape of lateral patches of hairs in the hood-shaped membrane, and by the lack of medial prominence in costal region of valva, in the male genitalia.

\section{Scotocyma longiuncus sp. n. (Figs $\mid 4,28,51,52,75$ )}

Types. Papua New Guinea. Holotype male, Finisterre Range, Gabumi, WWB, 23.vi.-21.vii.1958 (ANIC).

Description (Figs 14,28). Face blackish-brown scaled, with some ochreous scales at base of antennae. Labial palpus dark brown, with distinct white scales at base, with rings of whitish scales at base and at distal end of medial palpal segment. Forefemur anteriorly shining, pale yellowish, with dark brown scales along the sides. Abdomen apically brown. Wing expanse $41 \mathrm{~mm}$. Forewing above similar to S. scotopepla, brown to ochreous-brown, with median band darker, edged with a thin ochreous line, with basal band lighter than the rest of the wing, underneath yellowish in basal half, without thin brownish lines, with small medial and costal brown spots, with median band forming medial triangular projection outwards, 
edged with distinct, broad whitish band not interrupted medially, thick at the lower side of the medial triangular projection, with very large apical, medial and hind white square spots at the termen; costa slightly curved distally, apex slightly rounded. Hind wing above of the same colour as forewing, with discal dot not prominent, with wavy, ochreous and dark brown median and posterior lines, underneath coloured and patterned similar to forewing, with white band broader than in S. scotopepla.

Male genitalia (Figs 51,52). Uncus long, tapering, at base broader than in S. scotopepla, with medial kiel on its dorsal surface and a hook on its ventral surface distally; tegumen relatively narrow, at base with weakly sclerotised, serrated lateral arms; valva with costa sclerotised, twisted at base, setose in its medial region, with an apically projecting point, with apices hardly reaching the half height of uncus; vinculum U-shaped; calcar rather short, with apical hook smaller than in S. scotopepla, turned down, with hairs in its distal part; hood-shaped membrane with medium-sized, rounded lateral patches of hairs; aedeagus with a medial patch of weak scobination in vesica.

Female unknown.

Habitat. Rainforest, at an altitude of $600 \mathrm{~m}$.

Distribution (Fig. 75). Papua New Guinea.

Etymology. The species name refers to considerable length of the uncus in males.

\section{Scotocyma manusensis Prout stat. $\mathbf{n}$. (Figs I3, I 5, 29,39,47,48,70,75)}

Scotocyma albinotata manusensis Prout (1940): 293.

Types. Papua New Guinea. Admiralty Islands. Manus Island. Lectotype male, [ASM], ix.-x.1913 (BMNH); this specimen is here designated lectotype so as to fix and stabilise the current concept of the name and has been so labelled (examined). Paralectotypes: 1 male, 1 female, same data as lectotype (examined).

Description (Figs 13,15,29). Face brown scaled, with light brown and pale ochreous scales at base of antennae. Labial palpus brown, with whitish scales at base and distinct rings of whitish scales at distal end of medial palpal segment. Forefemur anteriorly shining, pale yellowish, with brown and light brown scales along the sides. Wing expanse 34-42 mm. Forewing above reddish-brown, with median band rather indistinct, edged with a very fine ochreous line, with a few postmedian wavy brownish lines, underneath yellow in basal half, with several brown dots, with median band forming medial triangular projection outwards, edged with whitish band, with medium-sized apical and medial white square spots at the termen; costa slightly curved distally, apex slightly rounded. Hind wing above of the same colour as forewing, with wavy brown and reddishbrown median and posterior lines, underneath coloured and patterned like forewing, with discal dot distinct, but with median band forming rounded projection outwards, and with additional white square spot at the anal angle.

Male genitalia (Figs 47,48). Uncus relatively long, broadened in its basal half, tapering in its distal half, slightly hooked distally; tegumen at base with short, weakly sclerotised, finely serrated lateral arms; valva slightly narrowed medially, with costa sclerotised, slightly twisted at base, setose in its medial region, with an apically projecting point; vinculum U-shaped; calcar large, with apical hook turned down, with thick hairs in its distal part; hood-shaped membrane with medium-sized, rounded lateral patches of hairs; aedeagus with a medial patch of very weak scobination in vesica.

Female genitalia (Fig. 70). Antrum heavily sclerotised, longitudinally folded; ductus bursae broad, very short, with a thin proximal ring of sclerotisation; corpus bursae bean-shaped, with dorsal, more or less triangular-shaped, longitudinally folded patch of sclerotisation, with proximal edge thorny, the convex side of corpus bursae with a row of small spines, with diverticulum larger than corpus bursae, drop-shaped, weakly membranous; signum a large rounded patch of very fine spicules.

Distribution (Fig. 75). Papua New Guinea (Manus Island).

Remarks. This species was described as subspecies of $S$. albinotata. In Scoble (1999) it is listed as a subspecies. Adults of $S$. manusensis differ from those of $S$. albinotata by the more reddish upper side of wings with less distinct median band, by the darker basal band in a forewing, by much brighter underside with yellow scales present, by much thinner, tapering, heavily sclerotised uncus, by finely serrated lateral arms of the tegumen, by larger calcar in the male genitalia, and by the much larger signum consisting of finer spicules in the female genitalia.

\section{Scotocyma mimula Warren stat. $\mathrm{n}$. (Figs 20,30,65,75)}

Paragramma mimula Warren (1905): 425.

Scotocyma albinotata mimula (Warren): Prout (1940): 293 (as subspecies).

Scotocyma albinotata (Walker 1866): McQuillan and Edwards (1996): 228 (as syn. n.).

Scotocyma albinotata mimula (Warren): Scoble (1999): 869 (as subspecies).

Types. Papua New Guinea. Bougainville. Holotype female (ASM], v.1904 (BMNH) (examined).

Description (Figs 20,30). Face brown scaled, with whitish medial triangular spot. Labial palpus brown to dark brown, with rings of whitish scales at base and distal end of medial palpal segment. Forefemur anteriorly whitish, with brown scales along the sides. Wing expanse $36 \mathrm{~mm}$. Forewing above ochreous- to greyish-brown, with median band rather indistinct, with tooth-like medial projection indistinct, continuing into a paleish streak towards tornus, which interrupts the darker marginal area, underneath bright yellow in basal half, with several small scattered brown spots, with median band forming medial triangular projection outwards, edged with whitish band, with medium-sized apical and medial whitish square spots at the termen; costa strongly curved distally, apex slightly rounded. Hind wing above pale ochreous-brown in the basal half, with four thin brown wavy bands, brown in the marginal half, underneath similar to the forewing, with discal dot distinct, 
but with median band forming rounded projection outwards, and with additional white square spot at the anal angle.

Male unknown.

Female genitalia (Fig. 65). Antrum heavily sclerotised, longitudinally folded; ductus bursae broad, very short, weakly sclerotised proximally; corpus bursae almost spherical, flatterned on its right side, with relatively small (less than half length of corpus bursae) dorsal, somewhat triangular-shaped, slightly longitudinally folded patch of sclerotisation, with diverticulum probably of the same size as corpus bursae, weakly membranous; signum a rather large, broad, shell-shaped patch of fine spicules arranged in rows.

Distribution (Fig. 75). Papua New Guinea (Bougainville).

Remarks. Scotocyma mimula was described as a species. Prout (1940) treated it as a subspecies of S. albinotata, and McQuillan and Edwards (1996) treated it as a synonym. In Scoble (1999) $S$. mimula is listed as a subspecies again. Adults of $S$. mimula differ from those of $S$. albinotata by the paler median band edged with thicker whitish band interrupted medially in a forewing above, by much brighter underside with bright yellow scales in the basal half, by the size and shape of dorsal patch of sclerotisation and by the size and shape of signum in corpus bursae of the female genitalia.

\section{Scotocyma miscix Prout (Figs 16, I 8, I 9, 2 I,33-35,40,53,54,63,75)}

Scotocyma miscix Prout (1934): 254.

Types. Fiji. Lectotype female, Vunidawa, H. Phillips, 5.ix.1932 (BMNH); this specimen is here designated lectotype so as to fix and stabilise the current concept of the name and has been so labelled (examined). Paralectotypes: 2 females, same data as lectotype (BMNH) (examined).

Other material examined. Fiji. One female, Vunidawa, H. Phillips, 2.i.1937 (BMNH); 7 males, 12 females, Nandarivatu, H.S. \& G.S. Robinson, 27-30.vi.1968, 15-17.viii.1969, 7.ii.1970 (BMNH); 1 male, Coloisuva, H.S. \& G.S. Robinson, viii.1968 (BMNH); 1 female, Viti Levu, Mt Victoria, G.S. Robinson, 24.xi.1970; 1 male, Suva, H.S. Robinson, xii.1974 (BMNH); 1 male, Nairayawa, R. Brown, O. Pellmyr, 2023.xi.1986 (NMNH); 1 male, Pacific Harbor, R.L., B.B. Brown, 5.xii.1986 (NMNH); 1 male, 14 km W Lami, R.L., B.B. Brown, 7-10.xii.1986 (NMNH).

Description (Figs 16,18,19,21,33-35). Face blackish-brown scaled, with light brown, reddish and purple-brown scales at base of antennae. Labial palpus brown, speckled with purplebrown and black scales, with fine rings of whitish scales at base and distal end of medial palpal segment. Forefemur anteriorly shining, pale yellowish, with purple, brownish and a few reddish scales along the sides. Wing expanse 35-42 mm. Forewing above dark brown to fuscous- and purple-brown, with median band usually dark brown or with extensive white or greyish blotching, edged with ochreous wavy line or white blotching, underneath brown to purple-brown, with yellowish scales in basal half, with costal brownish or blackish spots, with median band forming medial rounded projection outwards, edged with whitish band not interrupted medially, with small apical and medial whitish or yellowish square spots at the termen; costa slightly curved distally, apex slightly pointed. Hind wing above of the same colour as forewing, with wavy, ochreous and dark brown median and posterior lines, often with white or whitish medial spot near termen, sometimes with whitish double line or spot at the hind margin, underneath coloured and patterned similar to forewing.

Male genitalia (Figs 53,54). Uncus thin, tapering, hooked distally; tegumen reduced in size, without lateral arms at base; valva simple, slightly narrowed medially, with costa weakly sclerotised in its basal half, membranous in its apical half, setose in its medial region, with comb-like structures reduced to rows of hair, with sacculus sclerotised; vinculum elongated, V-shaped; calcar very thin, hooked upwards, with a small apical hair tuft, with lateral hair bunches attached in its medial part; hood-shaped membrane with very large lateral patches of thin hairs; aedeagus very thick, with a large ventral patch of long cornuti and a small oblique patch of thin short spines in vesica, with proximal coecum penis relatively large, with distal end finely thorned.

Female genitalia (Fig. 63). Apophyses posteriores und anteriores long for genus. Antrum very broad, weakly sclerotised, with a few oblique folds from sides to the medial line; ductus bursae finely longitudinally folded, very broad, especially at its proximal end, membranous; corpus bursae somewhat heartshaped, with corrugate patch of sclerotisation on its dorsal side, with diverticulum larger than corpus bursae, kidneyshaped, thick membranous, with corrugate sclerotised ring at the place of attachment of the diverticulum; signum a relatively small patch of finely thorned sclerotisation.

Habitat. Primary forest (Robinson 1975), at altitudes of 820 $1320 \mathrm{~m}$.

Distribution (Fig. 75). Fiji.

\section{PHYLOGENETIC ANALYSIS}

The main purpose of the analysis was to study phylogenetic relationships within the genus in relation to the distribution patterns, and to examine whether the genus is monophyletic. Rooting was by outgroup, although selection was not straightforward. Species of Scotocyma possess a number of unique characters that are not found in any of the other larentiine genera that could be regarded as related to Scotocyma. On the other hand, the wing colour and pattern of Scotocyma species superficially resemble those found in distantly related genera. A pragmatic approach had to be adopted: since species of the genus Scotocyma exhibit characters found in representatives of the tribe Xanthorhoini (see Discussion), most Australian xanthorhoine species were checked. The comparison of external and genital characters revealed that Scotocyma shows similarities with a group of Australian calcar-bearing species currently placed in Xanthorhoe Hübner: X. anthracinata (Guenée), X. propinqua (Turner) and X. strumosata (Guenée). These species fall only within the broadest concept of Xanthorhoe and might eventually be transferred to a separate new genus (PB McQuillan pers. comm. 1998). The Australasian 
genera Acodia Rosenstock and Austrocidaria Dugdale also have characters in common with Scotocyma, in particular the pectination in the male antenna, the shape of dorsal plate of the ring between the coremata and vinculum, and the shape of the aedeagus in male genitalia, the length of apophyses posteriores, the size of antrum, sclerotisations in corpus bursae, and the size of diverticulum in female genitalia. Other outgroup candidates were species of the genus Visiana, an IndoAustralian group of species which was separated from Xanthorhoe by Prout (1940) and treated as a genus by Holloway (1986). Although not all Visiana species listed in Scoble (1999) share the characters stated for that genus by Holloway (1997), Visiana s.l. has character states in common with species of Scotocyma. These characters are: a modified, partly very thin sclerotised basal area of the uncus, a fused tegumen and vinculum composing a broad ring, similar position and shape of the abdominal coremata, and presence of a sclerotised ring between the seventh and the eighth segments in males; short, broad at base papillae anales, with apices rounded, and presence of the diverticulum in corpus bursae in females. Taking all evidence into account, it seemed most appropriate to include two species of the genus Visiana s.l., namely $V$. sordidata (Moore) and ' $V$ '. excentrata (Guenée), as outgroup taxa for the phylogenetic analysis.

\section{Characters and states}

I used 50 morphological characters in the phylogenetic analysis. All multistate characters were treated as unordered and all characters had equal weight. Twenty-seven characters are binary, and the rest are multistate with three to seven states. The data matrix is given in Table 1.

1 Terminal segment of labial palpus: 0, distinct, although small, blunt; 1 , extremely small, oblique.

2 Antenna in males: 0, simple; 1, bipectinate.

3 Wings underneath: 0 , without contrasting bands; 1 , with distinct, contrasting bands only at the termen; 2 , with distinct, contrasting bands in medial area.
4 Forewing underneath with medial interruption in median band: 0 , present; 1 , absent.

5 Whitish median band in a forewing underneath: 0, speckled with darker scales in proximal half; 1, pure white.

6 Distinct, brownish median band in a forewing underneath: 0, with medial projection outwards broadly rounded; 1 , with medial projection outwards narrowly rounded; 2, with medial projection outwards speckled with scales of lighter colour; 3 , with medial projection outwards rather sharp.

7 Medial spot at the termen in a forewing underneath: 0 , relatively small, marginally speckled with darker scales; 1, large, higher than wide, marginally speckled with darker scales; 2 , medium sized, square, with distinct edges; 3, rather large, higher than wide, with inner margin distinct wavy.

8 Colour of medium-sized and large medial spots at the termen in a forewing underneath: 0, mainly pure white; 1 , whitish, with pale yellowish scales.

9 Number of areoles: 0 , one; 1, two.

10 Ring between the seventh and eighth abdominal segments in males: 0 , broad; 1 , thin; 2 , modified.

11 Dorsal plate of the ring: 0, developed, with distal edge almost straight; 1, developed, with distal edge bilobed; 2 , reduced in size, narrow.

12 Small medial sclerite attached to the ring between the seventh and eighth segments in males: 0 , absent; 1 , present.

13 Uncus: 0, tapering, not hooked apically; 1, tapering, hooked apically; 2, broadening, convex apically; 3, broadening, concave apically.

14 Uncus width: 0, broadest at base; 1, broadest in the middle; 2 , broadest apically.

15 Lateral tegminal arms: 0, absent; 1 , reduced due to the tegminal reductions; 2 , short (shorter than five times as long as wide); 3 , long (longer than six times as long as wide).

Table 1 Character matrix of the genus Scotocyma

\begin{tabular}{|c|c|}
\hline Taxon & $\begin{array}{r}11111111112222222222333333333344444444445 \\
12345678901234567890123456789012345678901234567890\end{array}$ \\
\hline 'Visiana' excentrata & $101-----1200000-002100000000001601000-0-000-0-0---$ \\
\hline Visiana sordidata & $110-----10000030001010013002110-10011-0-05100-1000$ \\
\hline Scotocyma albinotata & $0020000-011122211100211021100010201120111211101210$ \\
\hline Scotocyma legalis & $0020000-011131221100211021100010201120111211111210$ \\
\hline Scotocyma samoensis & $0021000-011132221100211021100013201121111212121210$ \\
\hline Scotocyma rutilimixta & 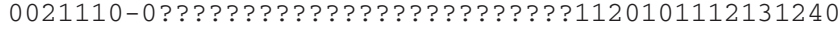 \\
\hline Scotocyma asiatica & 0021121101113223110131102110001120 ?? ?????? ?? ?? ? ?? \\
\hline Scotocyma sumatrensis & 00211111011132231101311021100014201120101212101210 \\
\hline Scotocyma scotopepla & 0021133001111121110010102110001220 ?? ?????????????? \\
\hline Scotocyma longiuncus & 0021133001111021110010102110001220 ?? ?? ?? ? ?? ?? ?? ? \\
\hline Scotocyma manusensis & 00211320011110231100101021100012201120101312101221 \\
\hline Scotocyma mimula & 002113200 ? ? ? ? ? ? ? ? ? ? ? ? ? ? ? ? ? ? ?? ? 1120101312101231 \\
\hline Scotocyma miscix & $0021000-0121101-1130-00011110015211121121413141152$ \\
\hline
\end{tabular}


Teeth on lateral tegminal arms: 0 , absent; 1 , moderately developed; 2, strongly developed; 3, almost reduced.

Shape of valva: 0 , not narrowed medially, like in most larentiine species; 1 , narrowed medially.

Valva: 0, narrowly connected to the vinculum in their lower half; 1 , broadly connected to the vinculum.

Apical process of costa valva: 0 , not protruding beyond the valval lobe; 1 , protruding beyond the valval lobe apically; 2 , protruding beyond the valval lobe at some distance from the apex; 3 , absent.

20 Costa valva: 0, almost parallel to the upper margin of valva; 1 , terminates at some distance from the apex of the upper margin of valva.

21 Shape of sclerotisation of costa valva: 0 , shifted from the upper margin; 1, narrow, spine-shaped; 2, relatively broad, not spine-shaped; 3 , very broad, concave apically.

22 Upper margin of costa valva: 0 , without prominence; 1 , with at least one prominence.

23 Twist at base of costa valva: 0 , absent; 1 , present.

24 Basal process of costa valva: 0, absent; 1, present.

25 Valval sacculus: 0 , simple; 1 , weakly sclerotised, with a small projection; 2, membranous, with rounded projection; 3 , slightly protruded, narrowed, curved ventrad.

26 Broadening at the sacculus of valva: 0, absent; 1, present.

27 Comb-like structures or their rudiments close to sacculus: 0 , absent; 1 , present.

28 Calcar: 0, present, hooked downwards; 1, present, hooked upwards; 2 , absent.

29 Papillae of juxta: 0, absent; 1, present.

30 Rounded basal lobes of juxta connected to the sacculi of valvae: 0 , present; 1 , absent.

31 Hood-shaped membrane: 0, absent; 1, present.

32 Size of hood-shaped membrane and hair patches: 0 , broad, with lateral hair patches small, rounded, with hairs thick; 1, broad, with lateral hair patches small, oval, with hairs thick; 2, broad, with lateral hair patches medium sized, oval, with hairs thin; 3 , broad, with lateral hair patches medium sized, rounded, with hairs thick; 4 , broad, with lateral hair patches medium sized, oval, with hairs thick; 5, broad, with lateral hair patches very large, with hairs thin; 6 , narrow, without hair patches.

33 Length of aedeagus: 0, more than eight times as long as wide; 1 , four to seven times as long as wide; 2 , two to three times as long as wide. Aedeagal cornuti: 0, absent; 1, present. Apophyses anteriores: 0, not thickened; 1, thickened. Length of apophyses posteriores: 0, more than twice as long as apophyses anteriores; 1, less than twice as long as apophyses anteriores.

38 Shape of large antrum: 0, narrowed proximally; 1, not narrowed proximally.
39 Folds of sclerotisation in antrum: 0, absent; 1, present.

40 Size and number of folds of sclerotisation in antrum: 0 , thin, more than three on each side; 1 , rather broad, firm, two to three on each side; 2 , very broad, rather soft.

41 Sclerotisation in corpus bursae: 0, present; 1 , absent. 42 Shape of corpus bursae: 0, globular, without asymmetric prominence at the ductus; 1 , globular, with asymmetric prominence at the ductus; 2, ovoid, with asymmetric prominence at the ductus; 3 , asymmetric, tending to bean-shaped; 4 , heart-shaped; 5 , in shape of boxing glove.

Diverticulum of corpus bursae: 0 , absent; 1 , present.

44 Size and shape of diverticulum of corpus bursae: 0 , small; 1, large, elongate-ovoid; 2, large, lemonshaped; 3, large, kidney-shaped.

Distinct patch of rough sclerotisation in corpus bursae: 0 , absent; 1 , present.

Shape of the patch of rough sclerotisation in corpus bursae: 0, somewhat triangular shaped, folded, projecting proximally; 1, elongate, tongue-shaped, folded; 2, C-shaped; 3, shortened, tongue-shaped, partly folded, rounded proximally; 4 , corrugate.

47 Signum: 0, absent; 1, present.

48 Size of signum: 0, small; 1, medium sized, less than one-third of width of corpus bursae; 2, large, half of width of corpus bursae.

49 Shape of signum: 0, a spot of inwardly directed spicules; 1, drop-shaped; 2, rounded; 3, shell-shaped, with spicules arranged in firm rows; 4, shell-shaped, with spicules arranged in soft rows; 5, relatively small, rounded patch of finely thorned sclerotisation.

Position of signum in corpus bursae: 0, more or less medial; 1 , shifted to the side; 2 , shifted proximally.

\section{RESULTS AND DISCUSSION}

\section{Phylogenetic analysis and monophyly of the genus Scotocyma}

The analysis of the data matrix containing 11 ingroup and 2 outgroup taxa using a branch and bound search produced three most parsimonious trees of length 100 steps (consistency index $(\mathrm{CI})=0.94$, retention index $(\mathrm{RI})=0.89)$. All three trees differ only in the placement of the two species $S$. manusensis and $S$. mimula within the group of four Papuan species. This is most probably caused by the presence of missing data for S. scotopepla and S. longiuncus, where only males and for S. mimula where only females are known. The strict consensus tree is presented in Figure 77.

The CI is determined to measure the amount of homoplasy in a given data set. In general, $\mathrm{CI}$ is dependent on the number of taxa included and it is affected by the amount of uninformative characters (Kitching et al. 1998). The CI in this analysis (0.94) is high compared with other studies including this number of taxa, clearly indicating a low level of homoplasy 
of the 50 selected characters. The RI is interpreted as a measure of synapomorphy, since not all similarities will be synapomorphies. The high value of RI in this analysis (0.89) indicates that a high proportion of the characters support the groupings resulting from the phylogenetic analysis. The robustness of the monophyly of the clades was tested using the branch support method. Bremer support for clades is represented by the number of extra steps required before a clade collapses in the consensus tree of all trees which are as long as or slightly longer than the most parsimonious trees (Bremer 1994). In this analysis all clades but one have support values between 1 and 7 (Fig. 77).

The following synapomorphies support the monophyly of the genus Scotocyma. Males: (1) small medial sclerite attached to the ring between the seventh and eighth segments present (Figs 37-40); (2) valva narrowed medially, broadly connected to the vinculum; (3) broadening at the sacculus of valva present; (4) comb-like structures or their rudiments on the valva close to the vinculum present. Females: (5) apophyses anteriores thickened; (6) the antrum folded; (7) the corpus bursae bears patches of scobinate or corrugate sclerotisation on its dorsal side; (8) a large diverticulum present. Males and females: (9) terminal segment of labial palpus distinct, although small and blunt; (10) one areole in the forewing in both sexes present.

\section{Sister-group relationships and distribution patterns of Scotocyma}

The genus has a wide distribution within the Australasian region ranging from western Sumatra, Borneo and Sulawesi through Papua New Guinea and New Caledonia to Fiji and Western Samoa, and eastern Australia (Figs 74,75). Although several species occur in the Australasian temperate areas and the subtropics, the genus is most species rich in the tropical montane region. Most species occur in rainforest areas at moderate elevations.

Species of Scotocyma seem to be rare, since few specimens were obtained in most areas, even where collecting has been strategic and intensive (e.g. Borneo, New Caledonia, Sumatra). Scotocyma albinotata in eastern Australia is an exception, with more than 80 specimens collected or reared. It is likely that many unknown species remain to be discovered, especially from the mountains of the poorly studied Melanesian islands. Therefore, the following biogeographical discussion can be considered as preliminary but it will provide useful data for future investigations.

A group for testing island interrelationships should be monophyletic and endemic to the areas of interest (Platnick \& Nelson 1978). Scotocyma is monophyletic and shows a considerable degree of endemism of its species, with all known species being endemics, except $S$. asiatica which occurs in northern Sulawesi and Borneo. Taking this into account, it is likely that the genus would provide some useful data on the area relationships in the Melanesian region, which has an extremely complex geotectonic history, and vice versa that the geological data could help to understand the biogeography of the genus. The geography of Scotocyma is not unique, and similar distribution patterns have been described for other insect groups, for instance, West Pacific cicadas (de Jong 1987; Duffels 1988; de Boer 1995).

The Scotocyma distribution pattern supports the hypothesis of the geological evolution of Melanesia which has been proposed and is supported by a number of geological (e.g. Gill \& Gorton 1973; Jaques \& Robinson 1977; Coleman 1980; Daly et al. 1991; Hall 1996, 1998, 2001) and biogeographical studies (e.g. Lieftinck 1942; Toxopeus 1950; Holloway 1970, 1979, 1984, 1986, 1987; Duffels 1988; de Boer 1995). This hypothesis suggests the independent development of two or more Melanesian island systems (most being chains of volcanic islands), which eventually collided in New Guinea. According to this hypothesis, the northern Moluccas, the northern spine of mountain ranges of Papua New Guinea, Bismarck Archipelago, Solomon Islands, Vanuatu, Fiji and Tonga may have comprised the Outer Arc (OMA in Fig. 76), whereas eastern Sulawesi, the southern Moluccas, the central spine of mountain ranges of Papua New Guinea, New Caledonia, with westerly extension up to Timor, easterly including northern New Zealand, comprised an Inner Arc (IMA in Fig. 76). The geological origin of the Samoan islands is quite different from the arcs above, representing oceanic island volcanism (Ewart 1988). Prior to the opening of the Tasman Sea, the older Inner Arc was adjacent to the eastern coast of Australia (Holloway 1979; Daly et al. 1991) and is actually not an island arc system, although some components (e.g. parts of Sulawesi, southern Moluccas) may be. Additionally, the uplift of the Lesser Sunda chain allowed biological exchange with tropical Australasia (Zeuner 1943). The breakdown of the Outer-Inner Arc system and the drift of its parts that created new barriers may have caused the vicariant evolution of the species on the fragments.

The distribution of the sister-species S. scotopepla and S. longiuncus in different mountain ranges in the south-east and north-east of Papua New Guinea, respectively, reflects the presumed original isolation of the Melanesian Arcs. As mentioned above, the geological origin of Papua New Guinea is of composite nature. Prior to the collision between the Australian plate and the Outer Melanesian Arc, no less than 32 tectonostratigraphic terranes (= fault-bounded fragments of the crust or lithosphere with its own characteristic stratigraphic sequence) of composite geological origin existed in the northern and eastern parts of New Guinea (Pigram \& Davies 1987). Approximately in the Miocene the East Papua composite terrane collided with the northwards moving Australian continent (Pigram \& Davies 1987) to form the Papuan Peninsula, now comprising the known distribution area of S. scotopepla (Figs 75,76). It was estimated that the Finisterre terrane joined New Guinea much later (Pigram \& Davies 1987). The Finisterre terrane comprises the Huon peninsula and the Finisterre range, which is the known distribution area of S. longiuncus (Fig. 75). Interestingly, Pigram and Davies (1987) also suggest that the Finisterre terrane might earlier have formed a single linear island arc segment with New Britain, New Ireland, Manus Island and Bouganiville Island which would perfectly 


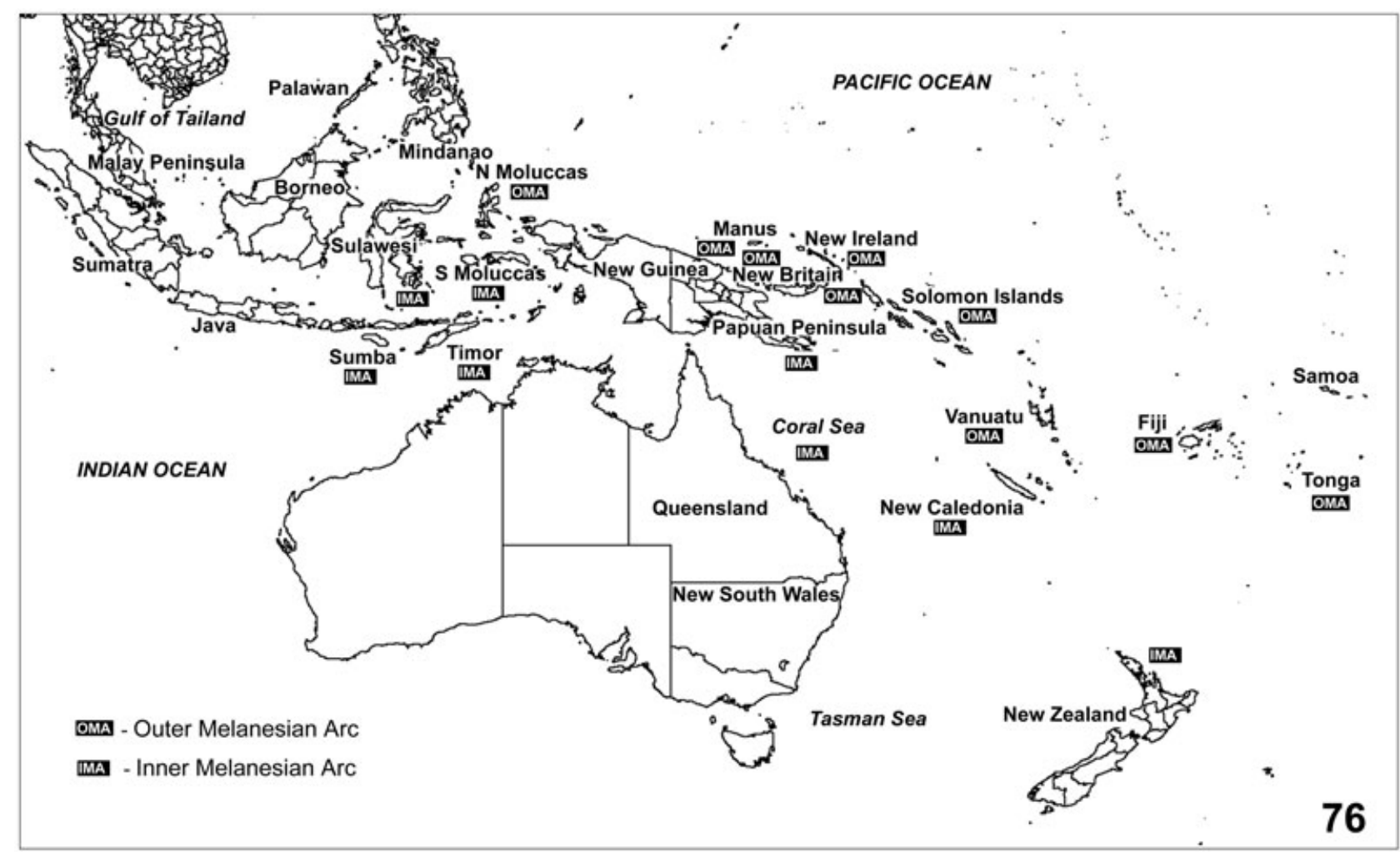

Fig. 76. Present-day map of south-east Asia and the West Pacific showing the approximate position of the Inner and Outer Melanesian Arcs.

explain the position of the Bougainville species, S. mimula, and the Bismarck Archipelago (Manus Island) species, S. manusensis, close to the S. scotopepla + S. longiuncusgroup on the cladogram (Fig. 77).

The highest Bremer support value of 2 (except the support for the basal node of the genus) is shown for the sister-taxa S. albinotata $+S$. legalis that occur in eastern Australia and in New Caledonia, respectively (Fig. 77). Both regions are part of the Inner Arc complex (Fig. 76). This type of distribution pattern was described by Holloway $(1979,1984)$ as 'Coral Sea' element of an Inner Arc type which is strongly represented in Australasia. Exchange between the eastern coast of Australia and New Caledonia, probably primarily from the former to the latter, would have been facilitated by the exposure of the Chesterfield Reefs and other intervening areas during the Pleistocene glaciations (Holloway 1979). The Samoan species $S$. samoensis appears to be closely related to the clade comprising $S$. albinotata $+S$. legalis, but not to the Fijian species $S$. miscix which is attributed to the Outer Arc (Figs 75,76). Scotocyma miscix is isolated taxonomically like a large number of previously recorded Fijian species of Lepidoptera from different families (Robinson 1975; Holloway 1979, 1983, 1984). The question of the relative geographical relationship of the Samoan region currently is unresolved, apart from indications that the volcanic islands in this area have emerged about 13.5 Ma ago, grown, eroded and eventually subsided in an east to west progression, so that an old fauna existing on the 'proto-islands' in order to persist today would have to have undertaken periodic eastwards migration

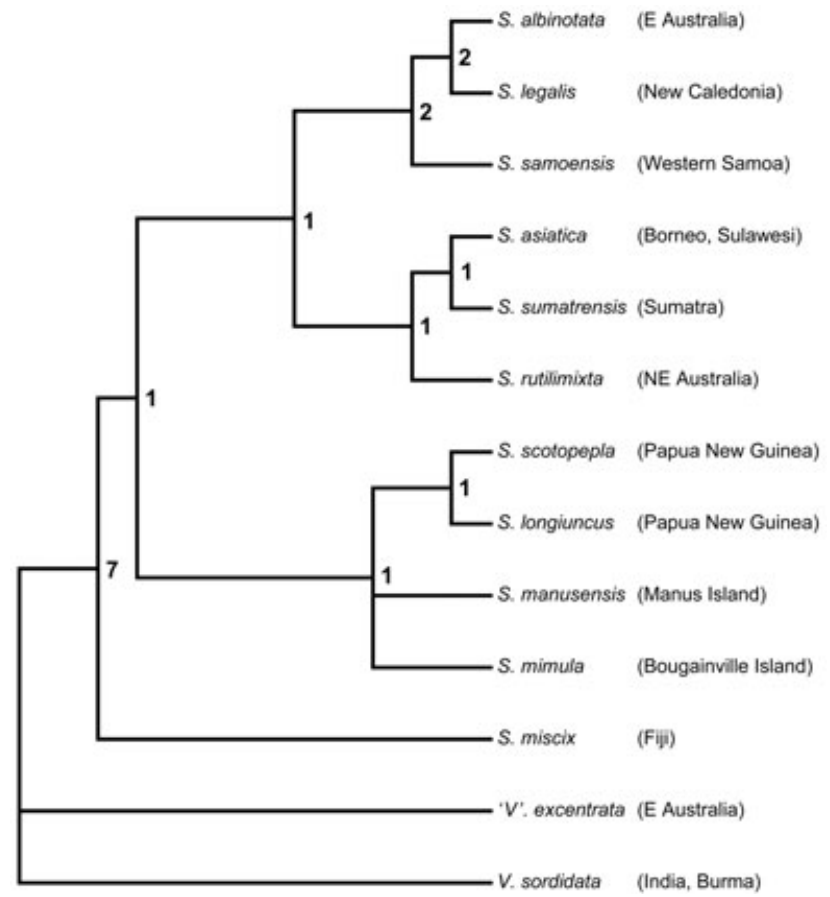

Fig. 77. Strict consensus tree for Scotocyma spp. Branch support for the nodes is shown.

as the archipelago continued to evolve (Natland 1980; Ewart 1988). The Samoan region presumably has never been a part of the Vanuatu-Fiji-Tonga volcanic ridge which existed until the Middle Miocene or Pliocene (Gill \& Gorton 1973). This 
corresponds to the placement of S. miscix and S. samoensis in different parts of the cladogram (Fig. 77). However, close relationship of the latter species to the Australian-New Caledonian one remains to be explained.

According to the phylogenetic analysis, the MalaysianIndonesian species S. asiatica is the sister species of the Sumatran species S. sumatrensis (Fig. 77). Considering the geological evidence, Sundaland, comprising the Malay Peninsula, Palawan, Java, Sumatra and Borneo, formed a landmass several times during the Pleistocene. The low-lying central portion of this land-mass was occupied by a large river system which played an important role in the species distribution in the region (Zeuner 1943), which could explain the sister-group relationship of S. asiatica and S. sumatrensis. However, the occurrence of S. asiatica both in northern Sulawesi and in Borneo is rather atypical for the genus, considering the endemism of all other species (Figs 74,75,76). According to a well-supported hypothesis (Zeuner 1943; van Bemmelen 1949), Sulawesi emerged in two separate localities (north-west and east) in the Miocene (Daly et al. 1991; Hall 2001) and subsequently has been pushed westwards towards Borneo by the northwardly drifting Australian continent. The theory of a drifting Australian block during and since the Tertiary was applied by Wegener (1924) and developed by a number of subsequent studies (e.g. du Toit 1937; Daly et al. 1991). The distribution of S. asiatica cannot be explained in terms of the hypothesis of the geological evolution of Melanesia because even during the low sea-level phases of the Pleistocene, no land connection was established between Sulawesi and Sundaland (e.g. Borneo) (Zeuner 1943). In this case an early long-distance dispersal may have occurred. According to the geotectonic evidences (Hall 2001) there was no direct way of crossing between Borneo and west Sulawesi but there were always routes from Borneo via Java into Sulawesi, by way of other small islands. Although this would explain the distribution of S. asiatica, there are other possibilities. A rather similar distribution pattern was examined in other insect orders, for instance, in cicadas of the Lembeja fatiloqua group (de Jong 1987; de Boer 1995; Holloway 1998). Those authors suggest that the connection with northern Borneo appeared to have been via Mindanao (Philippines) rather than direct from Sulawesi. Presumably, the geography of Scotocyma is only partially revealed at present. In case $S$. asiatica occurs in Mindanao the distribution pattern could be explained by the southerly dispersal. In general, Holloway (1986) emphasises the underestimating of dispersal events, especially in the evolution of the IndoAustralian montane biota.

The north-east Australian species S. rutilimixta is related to $S$. asiatica + S. sumatrensis and all those species presumably belong to the Inner Arc complex and its extension (Figs 74,76). The position of the Australian S. rutilimixta close to the Malaysian-Indonesian group but not to the New Caledonian species seems unexpected. Although males of this species are unknown (which produced some missing data in the character matrix), the adult morphology and the female genitalia show very distinct characters which did not group
S. rutilimixta together with the second Australian and the New Caledonian species S. albinotata and S. legalis.

Generally, the establishment of the ranges of ancestral taxa of a genus like Scotocyma across an initially dispersed archipelago could have required episodes of dispersal prior to the vacariant evolution (JD Holloway pers. comm. 2004). Hence, the complex disjunct distribution of species of the genus Scotocyma can be attributed to vicariance events caused by fragmentation of the Melanesian island arc system (like all Papuan species and S. miscix) and by long distance dispersal events which provide a more plausible explanation for the distribution of S. legalis and S. asiatica.

\section{Xanthorhoini and the tribal position of Scotocyma}

Xanthorhoini is a large cosmopolitan tribe of the larentiine moths. Despite numerous contributions of lepidopterists (Forbes 1948; McGuffin 1958; Herbulot 1961-1962; Heitzman \& Enns 1978; Hodges et al. 1983; Holloway 1986, 1997; Patočka 1995; McQuillan \& Edwards 1996; Viidalepp 1996; Leraut 1997), the tribal concept remains largely unresolved. This is partly due to lack of information about the tropical fauna and partly because of the limited choice of methods used to study tribal relationships.

Based on previous contributions and my own investigation, the following male genitalia characters can be regarded as typical for the tribe: (1) reduction in size of the seventh abdominal segment; (2) presence of broad eversible coremata pockets at the sides of the seventh segment, usually with spiracles ventrally; (3) usual absence of basal processes at costa valva; (4) presence of calcar or its rudiments fused with the juxta medially; and (5) somewhat rod-shaped sclerites or their derivates, or rudiments at juxta laterally. In adults, the presence of a median band which usually forms a projection outwards, and wavy bands in the forewing can as well be considered as characteristic of the tribe. However, those characters occur also in a few other larentiine tribes.

The following characters typical for the tribe Xanthorhoini were found to be present in Scotocyma: (1) seventh abdominal segment reduced in size; (2) broad coremata present in males, consisting of eversible hair tufts in a broad pocket laterally on each side of the seventh segment, with spiracles on the pockets ventrally; (3) basal processes at costa valva absent; (4) a welldeveloped, curved and apically setose calcar present, arising medially between the bases of the valves. Also, the wing pattern of Scotocyma species is typical for the tribe Xanthorhoini, with a median band in the forewing forming a toothlike projection outwards and with thin wavy bands.

Comparison of Scotocyma with several non-Australasian xanthorhoine genera revealed several other similarities which, apart from the characters listed above, potentially constitute additional synapomorphies. For instance, in the male genitalia of species of the genus Epirrhoe Hübner there is a hair tuft on the valval sacculus, which resembles the comb-like structures found in all species of Scotocyma. Furthermore, patches of sclerotisation in corpus bursae, which are characteristic of 
Scotocyma, are present in females of several xanthorhoine genera, for example, Scotopteryx Hübner and Epirrhoe, although they are not folded in these genera. Also, the shape and colour pattern of the larva of S. albinotata agree with characters found in other xanthorhoine larvae. The known food plant of S. albinotata, C. repens, belongs to the family Rubiaceae. Other genera from this family (e.g. Galium) are known food plants of many European members of the tribe Xanthorhoini (e.g. Catarhoe Herbulot, Costaconvexa Agenjo, Epirrhoe, Orthonama Hübner and several Xanthorhoe species). Species of the two Australasian xanthorhoine genera Acodia and Austrocidaria which are closely related to Scotocyma are known to feed on Coprosma (Dugdale 1964, 1971, 1988; McQuillan 1999). All the above-mentioned characters support the placement of Scotocyma in the tribe Xanthorhoini.

\section{Checklist of the genus Scotocyma}

$\begin{array}{cl}\text { Scotocyma Turner (1904) } \\ 1 & \text { albinotata (Walker 1866) (Scotosia) } \\ & \text { platydesma (Lower 1894) (Xanthorhoe?) } \\ & \text { euryochra Turner (1922), syn. n. } \\ & \text { idioschema Turner (1922), syn. n. } \\ & \text { ischnophrica Turner (1932), syn. n. } \\ & \text { transfixa Turner (1931); syn. n. } \\ 2 & \text { legalis (Warren 1896) (Coenocalpe?) } \\ 3 & \text { samoensis, sp. n. } \\ 4 & \text { rutilimixta, sp. n. } \\ 5 & \text { asiatica Holloway (1997) } \\ 6 & \text { sumatrensis, sp. n. } \\ 7 & \text { scotopepla Prout (1940), stat. n. } \\ 8 & \text { longiuncus, sp. n. } \\ 9 & \text { manusensis Prout (1940), stat. n. } \\ 10 & \text { mimula (Warren 1905) (Paragramma), stat. n. } \\ 11 & \text { miscix Prout (1934) }\end{array}$

\section{ACKNOWLEDGEMENTS}

The study was conducted at the following institutions: CSIRO Entomology (Canberra, Australia), Staatliches Museum für Naturkunde (Stuttgart, Germany), The Natural History Museum (London, UK), Zoologische Staatssammlung München (Munich, Germany). Chris Burwell (QM), Maree Darrell (MMUS), Ted Edwards (ANIC), Mark Epstein (NMNH), Steve Heydon (University of California, Davis), Martin Honey (BMNH), Scott Miller (NMNH), Max Moulds (AMSA), Vanna Rangsi (ANIC), Al Samuelson (BPBM), Manfred Sommerer (Munich), Ken Walker (DEMV) are thanked for the loan of material. Special thanks to Jeremy Holloway (BMNH) and Gaden Robinson (BMNH) for providing me with the specimens of a new Samoan species. Sincere thanks to Jeremy Holloway for useful comments on the manuscript and in particular for advise on modern biogeographical literature, to Peter McQuillan (University of Tasmania, Hobart) for sharing information on Tasmanian Geometridae, and to Don Herbison-Evans (MMUS) for the information about larva and food plant of S. albinotata, for the loan of specimens and for the permission to publish the larval photographs. Many thanks to Stefan Schmidt (ZSM) for help with the phylogenetic analysis.

\section{REFERENCES}

Bremer K. 1994. Branch support and tree stability. Cladistics 6, 369-372. Coleman PJ. 1980. Plate tectonics background to biogeographic development in the Southwest Pacific over the last 100 million years. Palaeogeography, Palaeoclimatology, Palaeoecology 31, 105-121.

Craw RC. 1986. Review of the genus Notoreas (sensu auctorum) (Lepidoptera: Geometridae: Larentiinae). New Zealand Journal of Zoology 13, 134-140.

Craw RC. 1987. Revision of the genus Helastia sensu stricto with description of a new genus (Lepidoptera: Geometridae: Larentiinae). New Zealand Journal of Zoology 14, 269-293.

Daly MC, Cooper MA, Wilson I, Smith DG \& Hooper BGD. 1991. Cenozoic plate tectonics and basin evolution in Indonesia. Marine and Petroleum Geology 8, 1-21.

de Boer AJ. 1995. Islands and cicadas adrift in the west-Pacific. Biogeographic patterns related to plate tectonics. Tijdschrift voor Entomologie 138, 169-241.

de Jong MR. 1987. Taxonomy and biogeography of Oriental Prasiini 3: the fatiloqua and parvula groups of the genus Lembeja Distant, 1892 (Homoptera, Tibicinidae). Tijdschrift voor Entomologie 130, 177-209.

du Toit AL. 1937. Our Wandering Continents. Oliver \& Boyd, Edinburgh, UK.

Duffels JP. 1988. The Cicadas of the Fiji, Samoa and Tonga Islands, Their Taxonomy and Biogeography (Homoptera, Cicadoidea). EJ Brill/ Scandinavian Science Press, Leiden, Netherlands.

Dugdale JS. 1964. Insects of Campbell island. Appendix. Lepidoptera: Geometridae. Pacific Insects Monograph 7, 607-623.

Dugdale JS. 1971. Entomology of the Aucklands and other islands south of New Zealand: Lepidoptera, excluding non-crambine Pyralidae. Pacific Insects Monograph 27, 55-172.

Dugdale JS. 1988. Lepidoptera - annotated catalogue, and keys to familygroup taxa. Fauna of New Zealand 14, 1-262.

Eriksson T. 1998. Autodecay 4.0 (Program Distributed by the Author). Department of Botany, Stockholm University, Stockholm, Sweden.

Ewart A. 1988. Geological history of the Fiji-Tonga-Samoan Region of the S.W. Pacific, and some palaeogeographic and biogeographic implications. In: The Cicadas of the Fiji, Samoa and Tonga Islands, Their Taxonomy and Biogeography (Homoptera, Cicadoidea) (ed. L Lyneborg), pp. 15-23. EJ Brill/Scandinavian Science Press, Leiden, Netherlands.

Forbes WTM. 1948. Lepidoptera of New York and neighbouring states, part 2. Cornell University Agricultural Experimental Station Memoir 274, 128-175.

Gill J \& Gorton M. 1973. A proposed geological and geochemical history of eastern Melanesia. In: The Western Pacific, Island Arcs, Marginal Seas, Geochemistry (ed. PJ Coleman), pp. 543-566. University of Western Australia Press, Perth, Australia.

Hall R. 1996. Reconstructing Cenozoic SE Asia. In: Tectonic Evolution of Southeast Asia. (eds R Hall \& DJ Blundell). Geological Society of London Special Publication 106, pp. 153-184.

Hall R. 1998. The plate tectonics of Cenozoic SE Asia and the distribution of land and sea. In: Biogeography and Geological Evolution of SE Asia (eds R Hall \& JD Holloway), pp. 99-131. Backhuys Publishers, Leiden, Netherlands.

Hall R. 2001. Cenozoic reconstructions of SE Asia and the SW Pacific: changing patterns of land and sea. In: Faunal and Floral Migrations and Evolution in SE Asia - Australasia (eds I Metcalfe, JMB Smith, M Morwood \& ID Davidson), pp. 35-56. AA. Balkema (Swets \& Zeitlinger Publishers), Lisse, Netherlands.

Heitzman RL \& Enns WR. 1978. Annotated list and keys to the geometrid subfamily Larentiinae (Lepidoptera: Geometridae) of Missouri. Transactions of the Missouri Academy of Sciences 12, 47-63.

Herbulot C. 1961-1962. Mise a jour de la liste des Geometridae de France. Alexanor 2, 117-124, 147-154. 
Hodges RW, Dominick T, Davis DR et al. (eds) 1983. Check List of the Lepidoptera of America North of Mexico. E.W. Classey \& Wedge Entomological Research Foundation, London, UK.

Holloway JD. 1970. The biogeographical analysis of a transect sample of the moth fauna of Mt Kinabalu, Sabah, using numerical methods. Biological Journal of the Linnaean Society 2, 259-286.

Holloway JD. 1979. A Survey of the Lepidoptera, Biogeography and Ecology of New Caledonia. Series Entomologica 15. W. Junk, The Hague, Netherlands.

Holloway JD. 1983. Mobile organisms in a geologically complex area: Lepidoptera in the Indo-Australian tropics. Zoological Journal of the Linnean Society 76, 353-373.

Holloway JD. 1984. Lepidoptera and the Melanesian arcs. In: Biogeography of the Tropical Pacific (eds F Radovsky, PH Raven \& SH Sohmer), pp. 130-169. Association of Systematic Collections and Bernice P. Bishop Museum, Honolulu, USA.

Holloway JD. 1986. Origins of the Lepidopteran faunas in high mountains of the Indo-Australian tropics. In: High Altitude Tropical Biogeography (eds F Vuilleumier \& M Monasterio), pp. 533-556. Oxford University Press, Oxford, UK.

Holloway JD. 1987. Lepidoptera patterns involving Sulawesi: what do they indicate of past geography? In: Biogeographical Evolution of the Malay Archipelago (ed. TC Whitmore), pp. 103-118. Clarendon Press, Oxford, UK.

Holloway JD. 1997. The Moths of Borneo: family Geometridae, subfamilies Sterrhinae and Larentiinae. Malayan Nature Journal 51, 1-242.

Holloway JD. 1998. Geological signal and dispersal noise in two contrasting insect groups in the Indo-Australian tropics: R-mode analysis of pattern in Lepidoptera and cicadas. In: Biogeography and Geological Evolution of SE Asia (eds R Hall \& JD Holloway), pp. 291-314. Backhuys Publishers, Leiden, Netherlands.

Jaques AL \& Robinson GP. 1977. The continent/island-arc collision in northern Papua New Guinea. BMR Journal of Australian Geology and Geophysics 2, 289-303.

Kitching IJ, Forey PL, Humphries CJ \& William DM. 1998. Cladistics. The Theory and Practice of Parsimony Analysis, 2nd edn. Oxford University Press, Oxford, UK.

Klots AB. 1970. Lepidoptera. In: Taxonomist's Glossary of Genitalia in Insects (ed. SL Tuxen), pp. 115-130. Munksgaard, Copenhagen, Denmark.

Leraut PJA. 1997. Liste Systématique et Synonymique des Lépidoptères de France, Belgique et Corse, 2nd edn. Alexanor, Paris, France.

Lieftinck MA. 1942. The Dragonflies (Odonata) of new Guinea and neighbouring Islands, VI. Treubia 18, 441-608.

Lower OB. 1894. New Australian Heterocera. Ex. Transactions of the Royal Society of South Australia 18, 77-113.

McGuffin WC. 1958. Larvae of the Nearctic Larentiinae. Canadian Entomologist, Supplement 8, 5-104.

McQuillan PB. 1999. Patterns of diversity in the phytophagous insects of southern Australia. In: Dampier 300. Program and Abstracts: Biodiversity in Australia 1699-1999 and Beyond (eds A George, M Harvey \& J Majer), pp. 65-66. Western Australian Museum, Perth, Australia.

McQuillan PB \& Edwards ED. 1996. Geometridae. In: Checklist of the Lepidoptera of Australia, Monographs on Australian Lepidoptera, Vol. 4 (eds ES Nielsen, ED Edwards \& TV Rangsi), pp. 200-228. CSIRO, Melbourne, Australia.

Maddison WP \& Maddison DR. 1992. MacClade: Analysis of Phylogeny and Character Coevolution, Version 3, Documentation. Sinauer Associates, Sunderland, USA.

Natland JH. 1980. The progression of volcanism in the Samoan linear volcanic chain. American Journal of Science, A 280, 709-735.

Nichols SW (ed.) 1989. The Torre-Bueno Glossary of Entomology. New York Entomological Society in corporation with American Museum of Natural History, New York, USA.

Patočka J. 1995. Die Puppen der Spanner Mitteleuropas, Unterfamilie
Larentiinae, Tribus Lythriini, Xanthorhoini, Larentiini und Cidariini. Deutsche Entomologische Zeitschrift 42, 139-174.

Pierce FN. 1914. The Genitalia of the Group Geometridae of the Lepidoptera of the British Islands. FN Pierce, The Elms, Dingle, Liverpool, UK

Pigram CJ \& Davies PJ. 1987. Terranes and the accretion history of the New Guinea orogen. Journal of Australian Geology and Geophysics 10, $193-212$

Platnick NI \& Nelson G. 1978. A method of analysis for historical biogeography. Systematic Zoology 27, 1-15.

Prout LB. 1934. Some new Geometridae (Lepidoptera) from Fiji. Stylops 3, 251-261.

Prout LB. 1940. Larentiinae. In: Die Gross-Schmetterlinge der Erde, Fauna Indo-Australica, Bd. 12 (ed. A Seitz), pp. 1-356. Alfred Kernen Verlag, Stuttgart, Germany.

Robinson GS. 1975. Macrolepidoptera of Fiji and Rotuma, a Taxonomic and Geographic Study. Classey, Farington, UK.

Schmidt O. 2001. The Australian species of Anachloris Meyrick (Lepidoptera: Geometridae: Larentiinae): taxonomy, male genitalia musculature and systematic position. Australian Journal of Entomology 40, 219-230

Schmidt O. 2002. A revision of the genus Chaetolopha Warren (Lepidoptera: Geometridae: Larentiinae) with a description of Parachaetolopha, Gen nov. Invertebrate Systematics 16, 703-733.

Schmidt O. 2003. Some results of taxonomic research on larentiine moths from the Australasian region. Spixiana 26, 204.

Scoble MJ. 1999. Geometrid Moths of the World: A Catalogue (Lepidoptera, Geometridae). CSIRO Publishing, Collingwood, Australia.

Swofford DL. 2002. PAUP*. Phylogenetic Analysis Using Parsimony (*and Other Methods), Version 4. Sinauer Associates, Sunderland, USA.

Toxopeus LJ. 1950. The geological principles of species evolution in New Guinea. In: Proceedings of the 8th International Congress of Entomology, Stockholm, 1948 (ed. AR Elfstrums), pp. 508-522. International Congress of Entomology, Stockholm, Sweden.

Turner AJ. 1904. Revision of Australian Lepidoptera. Family Geometridae. Proceedings of the Royal Society of Victoria 16, 218 284.

Turner AJ. 1922. Australian Lepidoptera of the group Geometrites. Transactions of the Royal Society of South Australia 46, 225-294.

Turner AJ. 1931. Revision of Australian Lepidoptera. Supplementary. Proceedings of the Linnean Society of New South Wales 56, 325-344.

Turner AJ. 1932. New Australian Lepidoptera. Transactions of the Royal Society of South Australia 56, 175-196.

van Bemmelen RW. 1949. The Geology of Indonesia. Government Printing Office, The Hague, Netherlands.

Viidalepp J. 1996. Checklist of the Geometridae (Lepidoptera) of the Former U.S.S.R. Apollo Books, Stenstrup, Denmark.

Walker F. 1866. List of the Specimens of Lepidopterous Insects in the Collection of the British Museum. Part XXXV, Supplement - Part 5. British Museaum, London, UK.

Warren MA. 1896. New species of Drepanidae, Thyrididae, Uraniidae, Epiplemidae, and Geometridae in the Tring Museum. Novitates Zoologicae 3, 335-419.

Warren MA. 1905. New species of Thyrididae, Uraniidae, and Geometridae from the oriental region. Novitates Zoologicae 12, 409438.

Wegener A. 1924. The Origin of Continents and Oceans. Methuen, London, UK.

Zeuner FE. 1943. Studies in the systematics of Troides Hübner (Lepidoptera, Papilionidae) and its allies; distribution and phylogeny in relation to the geological history of the Australasian Archipelago. Transactions of the Zoological Society 25, 107-184.

Accepted for publication 21 November 2004. 